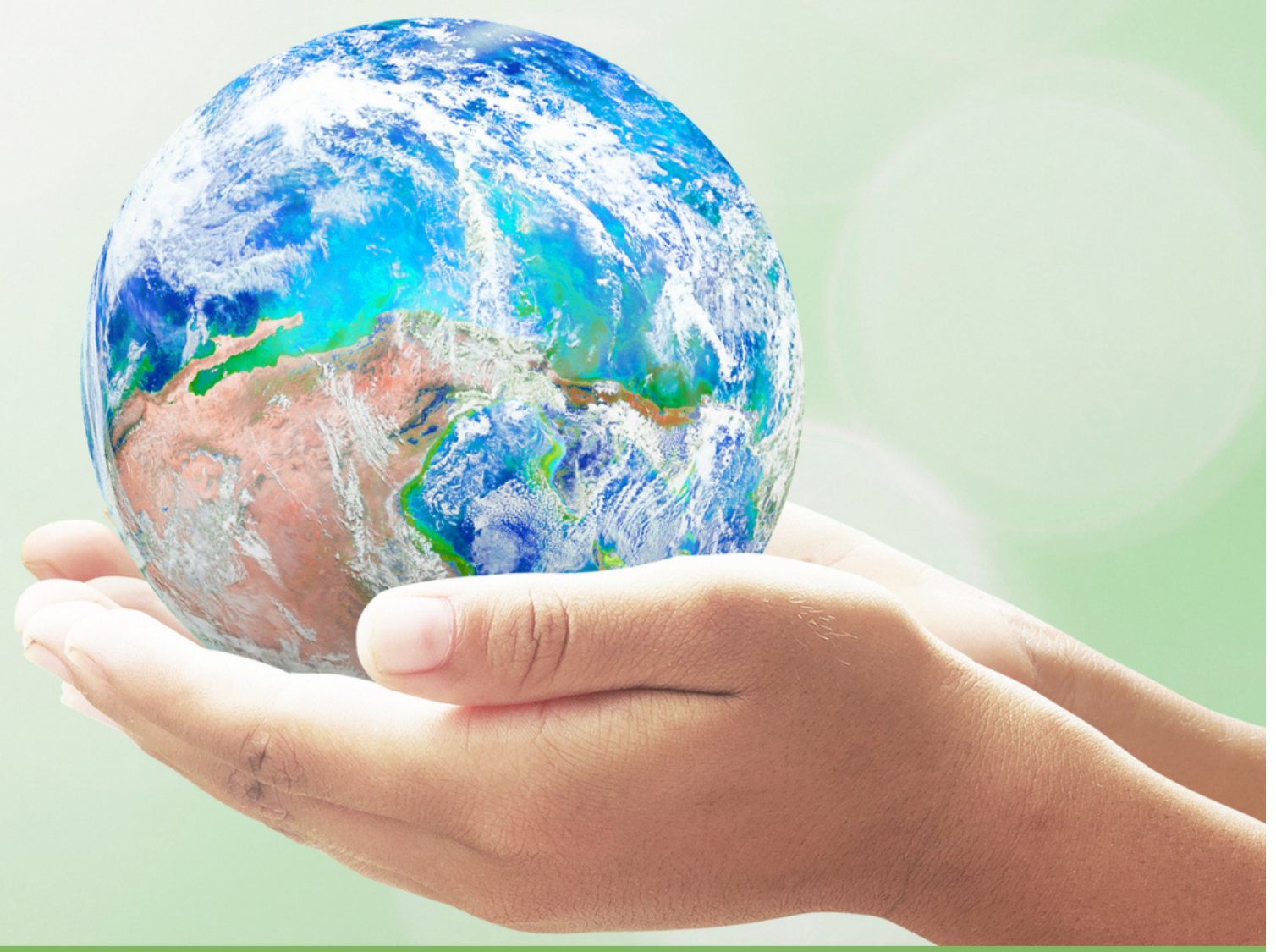

\title{
GEOCIÊNCIAS, SOCIEDADE \\ E SUSTENTABILIDADE
}

\section{VOLUME III}

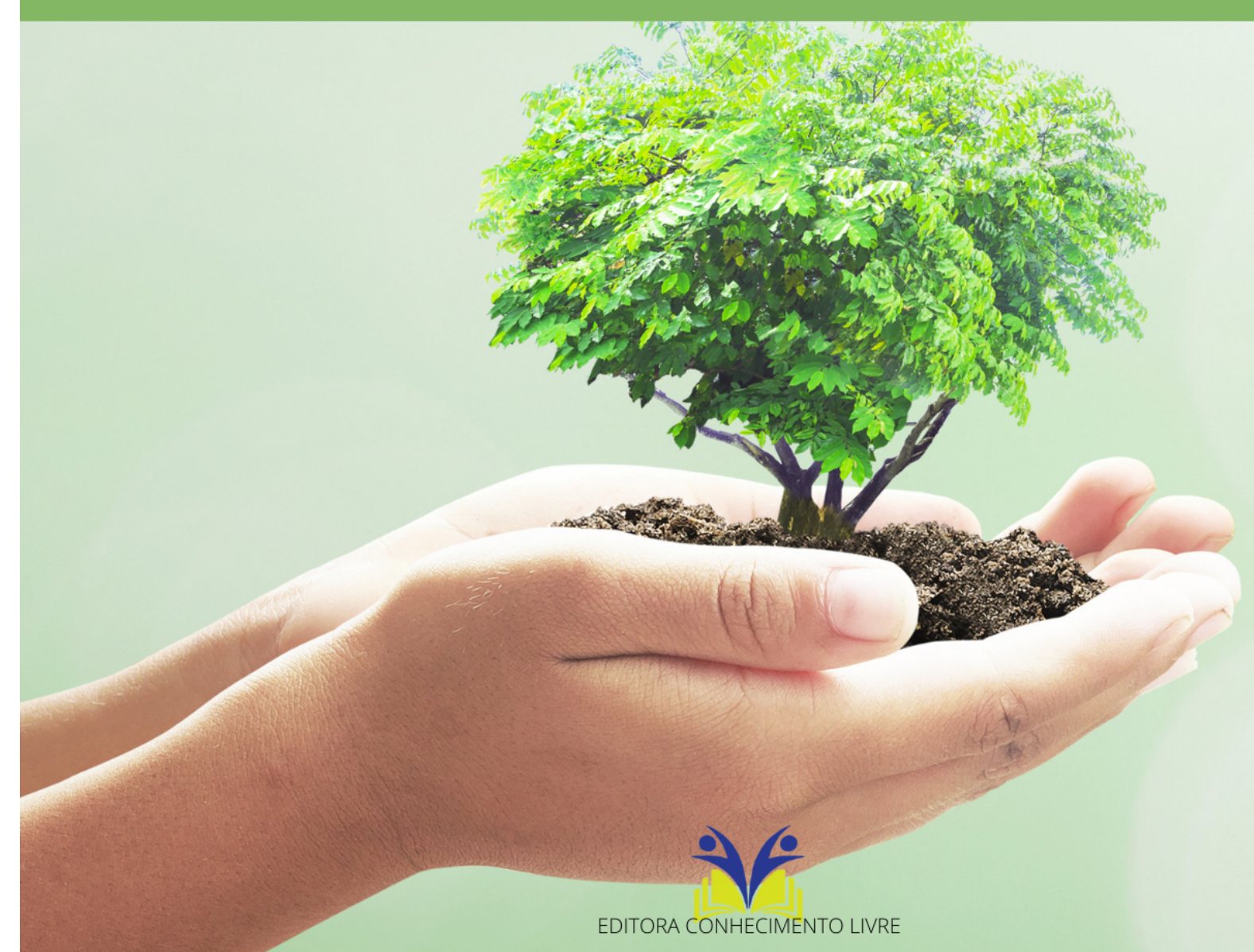


Frederico Celestino Barbosa

Geociências, sociedade e sustentabilidade

$3^{\text {a }}$ ed.

Piracanjuba-GO

Editora Conhecimento Livre

Piracanjuba-GO 
$3^{\mathrm{a}} \mathrm{ed}$.

\section{Dados Internacionais de Catalogação na Publicação (CIP)}

Barbosa, Frederico Celestino
B238G Geociências, sociedade e sustentabilidade

/ Frederico Celestino Barbosa. - Piracanjuba-GO

Editora Conhecimento Livre, 2021

45 f.: il

DOI: $10.37423 / 2021$. edcl392

ISBN: 978-65-5367-037-2

Modo de acesso: World Wide Web

Incluir Bibliografia

1. planeta 2. rochas 3. atmosfera 4. placas-tectônicas 5. oceanos I. Barbosa, Frederico Celestino II. Título

CDU: 550

https://doi.org/10.37423/2021.edcl392

O conteúdo dos artigos e sua correção ortográfica são de responsabilidade exclusiva dos seus respectivos autores. 


\title{
EDITORA CONHECIMENTO LIVRE
}

\section{Corpo Editorial}

\author{
Dr. João Luís Ribeiro Ulhôa \\ Dra. Eyde Cristianne Saraiva-Bonatto \\ MSc. Frederico Celestino Barbosa \\ MSc. Carlos Eduardo de Oliveira Gontijo \\ MSc. Plínio Ferreira Pires
}




\section{SUMÁRIO}

CAPÍTULO 1 5

AVALIAÇÃO SENSORIAL DE DOCE DE LEITE CAPRINO SABORIZADO COM CAFÉ

Wanderson de Lima Galvão

Talita Raniely Costa da Silva

Sérgio Henrique Barbosa

Barros da Silva, José

DOI 10.37423/211205141

CAPÍTULO 2

CARACTERIZAÇÃO AMBIENTAL, QUALIDADE DAS ÁGUAS E METAIS-TRAÇO DOS BOSQUES

DE MANGUE DA APA TINHARÉ-BOIPEBA, BAIXO SUL DA BAHIA (BR)

Manuel Vitor Portugal Gonçalves

Iracema Reimão Silva

Juan Carlos Rossi Alva

Manoel Jerônimo Moreira Cruz

Ana Carina Matos Silva

Maria do Carmo Filardi Barbosa

Flávio Souza Batista

Débora Carol Luz da Porciúncula

Thiago Guimarães Siqueira de Araújo

Gláucio Alã Vasconcelos Moreira

DOI 10.37423/211205183

CAPÍTULO 3

REVISÃO ESTRATIGRÁFICA DAS UNIDADES SUPERIORES DO SEGMENTO E-W DA FAIXA PARAGUAI: LITOESTRATIGRAFIA, QUIMIOESTRATIGRAFIA E GEOCRONOLOGIA, MT -

BRASIL.

Samille Cristine dos Reis de Souza

Carlos José Souza de Alvarenga

DOI 10.37423/220105216 


\section{Capítulo 1}

d.)

\section{AVALIAÇÃO SENSORIAL DE DOCE DE LEITE CAPRINO SABORIZADO COM CAFÉ}

Wanderson de Lima Galvão

Talita Raniely Costa da Silva

Sérgio Henrique Barbosa

Barros da Silva, José
Universidade Federal do Rio Grande do Norte

Universidade Federal do Rio Grande do Norte

Universidade Federal do Rio Grande do Norte

Universidade Federal do Rio Grande do Norte 
Resumo: O semiárido nordestino destaca-se no Brasil como uma região de grande potencial para o desenvolvimento da caprinocultura em função das condições ambientais favoráveis. O Rio Grande do Norte se posiciona como um dos maiores produtores de leite caprino pasteurizado do Brasil, sendo um exemplo para todo o Nordeste. Sob o aspecto nutricional, o leite caprino é rico em gorduras (ácidos graxos de cadeia curta e saturada), proteínas (aminoácidos essenciais), vitaminas A e B e sais minerais (cálcio, selênio, fosfato), cuja fração lipídica se reflete na coloração, sabor e odor característicos dos produtos derivados. O sabor e o odor característico desses derivados podem contribuir na restrição de consumo para paladares mais exigentes ou preconceituosos. Sendo, assim, o presente trabalho tem como objetivo desenvolver o doce de leite caprino saborizado com café e avaliar a aceitação e preferência como uma alternativa de agregação de valor sem o risco de rejeição do seu consumo. Diferentes formulações (tratamentos) de doce foram elaboradas variando-se a concentração de café solúvel (0,5\%; 1,0\%; e 1,5\%). A análise sensorial foi realizada por 60 avaliadores/consumidores de doce de leite e de café de diferentes faixas etárias. A escala hedônica estruturada de nove pontos, cujos extremos correspondem a desgostei extremamente (1) e gostei extremamente (9) foi utilizada no teste de aceitação dos doces elaborados. O teste de preferência foi aplicado na escolha da melhor formulação entre as três apresentadas aos avaliadores, visando explicitar as respectivas opiniões. A intenção de compra foi averiguada por meio da escala com variação entre "certamente compraria" e "certamente não compraria". O tratamento elaborado com $1 \%$ de café solúvel destacou-se entre as demais por ter apresentado as médias de todos os atributos superior a 7, revelando-se como o tratamento de maior aceitação por parte dos avaliadores/consumidores. Observou-se que a preferência pelo doce adicionado de 1,0\% de café solúvel destacou-se entre os dois tratamentos. Para os avaliadores que consumiram anteriormente leite caprino, os tratamentos 2 e 3 foram os que apresentaram o menor sabor residual característico. O doce adicionado de $1 \%$ de café apresentou a maior intenção de compra, enquanto que os doces adicionados de 0,5 e 1,5\% apresentaram incerteza de consumo, com predominância das alternativas "provavelmente compraria" e "talvez comprasse/talvez não comprasse.

Palavras-chave: Hábito alimentar, saborização de alimentos, agroindústria familiar, geração de renda. 


\section{INTRODUÇÃO}

O semiárido nordestino destaca-se no Brasil como uma região de grande potencial para o desenvolvimento da caprinocultura em função das condições ambientais favoráveis e da rusticidade da espécie caprina. Na Região Nordeste os estados da Bahia (33,4\%), Pernambuco (19,8\%), Piauí (16,8\%) e, somando-se ao Ceará (12,3\%), Paraíba (7,6\%) e Rio Grande do Norte (4,9\%) representam $94,8 \%$ do total do rebanho caprino (IBGE, 2009). O Rio Grande do Norte se posiciona como um dos maiores produtores de leite caprino pasteurizado do Brasil, sendo um exemplo para todo o Nordeste (ALMEIDA, 2010). Isso demonstra o quanto a caprinocultura leiteira significa para centenas de pequenos criadores em mais de 40 Municípios, produzindo um alimento nobre, gerando renda e assegurando a manutenção de alguns milhares de pessoas no campo e nas pequenas cidades. Acrescentam-se, ainda, os benefícios indiretos nos demais elos de sua cadeia produtiva agroindustrial. Por outro lado, nesse setor produtivo predomina criatórios que não potencializam, em seu conjunto, requerimentos e possibilidades que maximizem a eficiência dos agentes econômicos envolvidos e o desenvolvimento da cadeia produtiva. Dos 11.000 (onze mil) litros de leite produzidos, diariamente, no Rio Grande do Norte, apenas 2.800 (dois mil e oitocentos) são destinados aos laticínios para pasteurização e comercialização via "Programa Leite Potiguar" (PLP), portanto, havendo um excedente de grande parte da produção (RIO GRANDE DO NOTE, 2017). De acordo com Catunda et al. (2016), sob o aspecto nutricional, o leite caprino é rico em gorduras (ácidos graxos de cadeia curta e saturada), proteínas (aminoácidos essenciais), vitaminas A e B e sais minerais (cálcio, selênio, fosfato), cuja fração lipídica se reflete na coloração, sabor e odor característicos dos produtos derivados. O sabor e o odor característico desses derivados podem contribuir na restrição de consumo para paladares mais exigentes. Sendo, assim, o presente trabalho tem como objetivo desenvolver o doce de leite caprino saborizado com café e avaliar a aceitação e preferência como uma alternativa de agregação de valor sem o risco de rejeição do seu consumo.

\section{METODOLOGIA}

Material utilizado: leite caprino in natura, adquirido do setor de caprinocultura da Escola Agrícola de Jundiaí(EAJ), Campus da UFRN, Macaíba-RN; Café solúvel da marca Santa Clara ${ }^{\circledR}$ na versão clássica; Açúcar refinado e bicarbonato de sódio.

Foram realizadas análises físico-químicas do leite em aparelho EKOMILK ${ }^{\circledR}$ Milkana Kam 98-2A e verificação da acidez através de titulação com solução Dornic e indicador fenolftaleína a 1\%. Diferentes 
formulações (tratamentos) de doce de leite caprino foram elaboradas na Unidade de Processamento de Laticínios da EAJ-UFRN, variando-se a concentração de café solúvel: tratamento 1, 0,5\%, tratamento 2, 1,0\% e o tratamento 3, 1,5\% de café solúvel; os demais ingredientes foram adicionados em igual proporção, sendo 200g de açúcar para cada litro de leite e 3,6g de bicarbonato de sódio para cada 5 litros. Primeiramente, foram colocados no tacho o leite e parte (50\%) do açúcar, na devida proporção; logo após, adicionou-se bicarbonato para correção da acidez e em seguida os demais ingredientes, café solúvel e o restante do açúcar. O processo de concentração, com agitação, seguiu até atingir um teor de sólidos solúveis aproximado a 71 Brix, verificado por meio de refratômetro portátil. Após o resfriamento, os doces foram armazenados, sob refrigeração, até a realização das análises sensoriais.

A análise sensorial foi realizada por 60 avaliadores/consumidores de doce de leite e de café de diferentes faixas etárias. Foram oferecidos, aproximadamente, $20 \mathrm{~g}$ de cada formulação de doce em copos descartáveis codificados com números de três dígitos (951, 852 e 650) representando as amostras 1, 2 e 3, respectivamente. Os tratamentos foram apresentados de forma balanceada segundo Wakeling e McFie (1995). Foi fornecido biscoito "água e sal" e em seguida água, para limpeza do palato entre a avaliação dos tratamentos. As análises foram realizadas no ambiente da graduação, envolvendo alunos e professores da Escola Agrícola de Jundiaí-UFRN, no período da manhã, sob luz branca. A escala hedônica estruturada de nove pontos, cujos extremos correspondem a desgostei extremamente (1) e gostei extremamente (9) foi utilizada no teste de aceitação dos doces elaborados, conforme Stone e Sidel (1993). O teste de preferência consiste na escolha da melhor formulação entre as três apresentadas, sendo explicitado pelo avaliador/consumidor por meio da circulação do código do tratamento de sua preferência.

A intenção de compra foi averiguada pela escala com variação entre "certamente compraria" e "certamente não compraria". Os dados foram submetidos à análise exploratória, através de estatística descritiva.

\section{RESULTADOS E DISCUSSÃO}

Os resultados obtidos na análise sensorial dos doces encontram-se na Tabela 1, compreendendo as médias obtidas para cada atributo julgados pelos 60 avaliadores. 
Tabela 1 - Valores referentes aos atributos sensoriais de doce de leite caprino saborizado com café, conforme a escala hedônica.

\begin{tabular}{ccccc}
\hline Tratamento & Cor & $\begin{array}{c}\text { Atributo } \\
\text { Textura }\end{array}$ & Sabor & Aroma \\
\hline 1 & 7,6 & 7,8 & 7,6 & 7,2 \\
2 & 7,5 & 6,6 & 6,9 & 6,5 \\
3 & 6,3 & 6,2 & 6,7 & 7 \\
\hline
\end{tabular}

Tratamento: 1 = 0,5\% de café; 2 = 1,0\% de café; $3=1,5 \%$ de café.

Observa-se (Tabela 1) que, de modo geral, os doces obtiveram valores médios aproximados, situandose na região de "gostei ligeiramente" e "gostei moderadamente" (notas 6 e 7 da escala hedônica, respectivamente). 0 tratamento elaborado com $1 \%$ de café solúvel na formulação destacou-se entre as demais por ter apresentado as médias dos atributos superiores a 7, revelando-se como o tratamento de maior aceitação por parte dos avaliadores. Também, observa-se essa preferência dos avaliadores pelo doce adicionado de 1,0\% de café solúvel representado, graficamente, pela Figura 1 , numa situação intermediária em relação à concentração de café solúvel no doce avaliado, tendo a maioria absoluta (31) dos avaliadores/consumidores optado pelo doce de leite caprino com $1 \%$ de café.

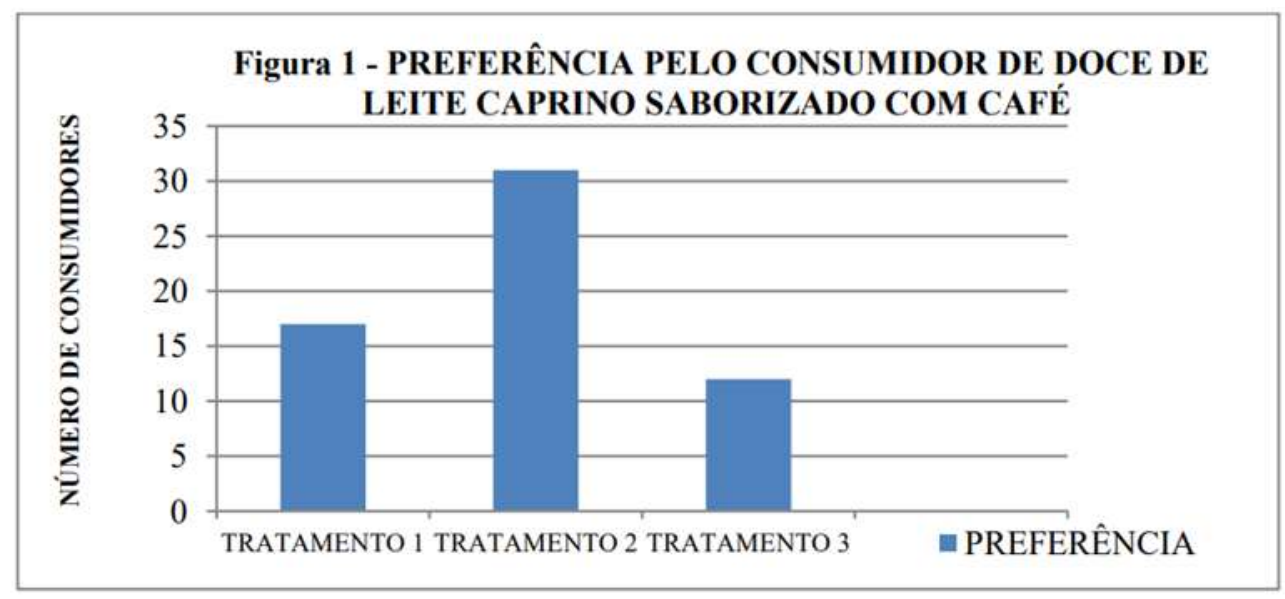

É possível observar (Figuras 2 e 3) a inter-relação entre hábito de consumo de leite caprino "in natura" e a percepção de descritores do respectivo derivado (doce) que, para os avaliadores os tratamentos 2 e 3 foram os que apresentaram a menor intensidade do sabor residual característico do leite. 


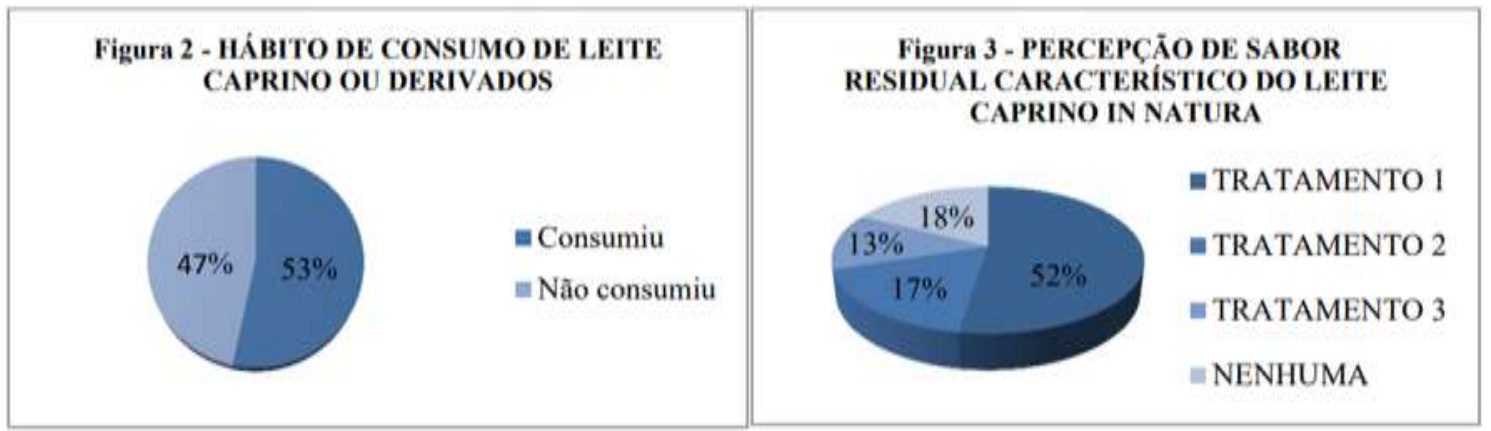

Essa situação pode ser atribuída à ação de maiores concentrações de café $(1,0$ e 1,5\%) presentes nestas formulações em sobrepor aos descritores restritivos às características organolépticas do leite caprino in natura. Entretanto, para 18\% (Figura 3) dos consumidores de leite caprino não foram percebidas essas características depreciativas nas formulações avaliadas. Já o tratamento com 0,5\% de café solúvel revelou, na análise sensorial, o maior percentual de sensibilidade ao perfil organoléptico característico do leite caprino in natura, podendo-se concluir que à medida que a concentração de café aumenta no doce de leite, torna-se menos perceptível aromas e sabores diferentes e de baixa aceitação.

A Figura 4 apresenta a intenção de compra expressada na análise sensorial do doce de leite caprino elaborado com níveis diferentes de café solúvel, variando numa escala estruturada nos termos de "certamente compraria" à "certamente não compraria", conforme opinião individual dos avaliadores/consumidores.

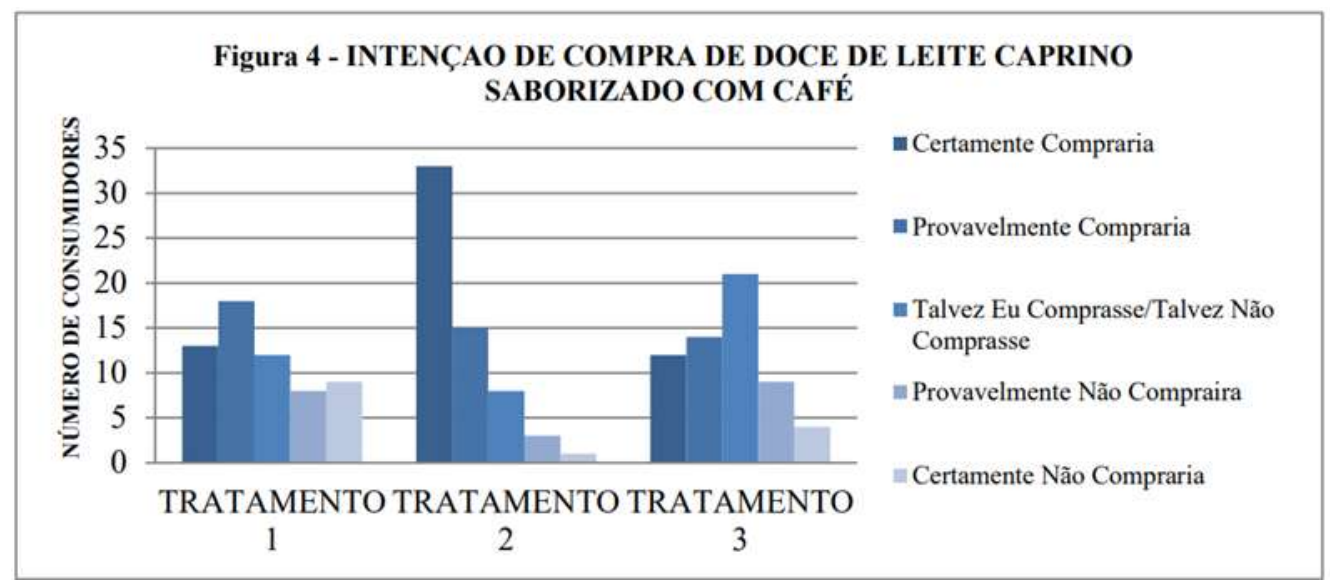

O doce adicionado de $1 \%$ de café apresentou a maior intenção de compra, uma vez que a alternativa "certamente compraria" ultrapassou cinquenta por cento dos avaliadores e a alternativa "certamente não compraria" situou-se próximo de zero. Quanto aos doces adicionados de 0,5 e 1,5\%, estes apresentaram incerteza de consumo, com predominância das alternativas "provavelmente compraria" e "talvez comprasse / talvez não comprasse. Portanto, o doce elaborado com a adição do 
nível intermediário (1\%) de café solúvel mostrou-se como a mais confiável sob o aspecto comercial. Barros da Silva et al. (2008), avaliando doce de leite bovino saborizado com café solúvel (0,5\%) confirmou a intenção de compra igual a 62,2\% (certamente compraria) e propondo, na conclusão do estudo, que o hábito tradicional do café com leite, certamente, influenciou nos resultados.

\section{CONCLUSÕES}

O doce de leite caprino saborizado com café obteve aceitação pelos consumidores e apresentou potencial de comercialização de acordo com os resultados da intenção de compra do produto.

As diferentes concentrações de café adicionadas no processo de elaboração do doce de leite caprino influenciaram na preferência do consumidor, apresentando como mais preferido o produto elaborado com $1 \%$ de café solúvel. Quanto à intenção de compra, também, o doce adicionado de $1 \%$ de café solúvel recebeu os valores superiores atribuídos pelos avaliadores.

A adição de níveis crescentes de café solúvel na formulação do doce de leite caprino mostrou-se diretamente relacionadas à eficiência na sobreposição das características organolépticas menos aceitas da matéria-prima, leite in natura. 


\section{REFERÊNCIAS}

ALMEIDA, V. T.; NOBRE, F. V. Caprinovinocultura no Estado do Rio Grande do Norte, entre 2004 e 2009: Alguns Aspectos Sobre Produção e Mercado.

BARROS DA SILVA, J, BARBOSA, I. M.; SANTOS, I. M.; COSTA, A. A.; SANTOS; G. C. R.; FERREIRA, A. M. Avaliação sensorial de doce de leite sabor café. In: XXI Congresso brasileiro de ciência e tecnologia de alimentos. Belo Horizonte-MG, 2008.

CATUNDA, K. L. M.; AGUIAR, E. M.; SILVA, J. G. M.; RANGEL, A. H. N. Leite caprino: características nutricionais, organolépticas e importância do consumo. Revista Centauro, v.7, n.1, p 34 - 55, 2016.

IBGE. Produção da Pecuária Municipal, 2009. Disponível em:

https://biblioteca.ibge.gov.br/visualizacao/periodicos/84/ppm_2009_v37_br.pdf. Acesso em Setembro de 2017.

RIO GRANDE DO NORTE. Programa Leite Potiguar (PLP), Lista Dos Fornecedores Laticinistas Credenciados. Termo de Homologação publicado no Diário Oficial do Estado do Rio Grande do Norte (DOE) no 13840 em 06 de janeiro de 2017.

STONE, H. S.; Sidel, J. L. Sensory evaluation practices. San Diego: Academic, 1993. 308p.

WAKELING, I. N.; MAC FIE, H. J. H. Designing consumer trials balanced for first And higher orders of carry-over effect when only a subset of k samples from t may be tested. Food Quality and Preference, Barking, v. 6, n. 4, p. 299-308, 1995. 


\section{Capítulo 2}

d

\section{CARACTERIZAÇÃO AMBIENTAL, QUALIDADE DAS ÁGUAS E METAIS-TRAÇO DOS BOSQUES DE MANGUE DA APA TINHARÉ-BOIPEBA, BAIXO SUL DA BAHIA (BR)}

Manuel Vitor Portugal Gonçalves

Iracema Reimão Silva

Juan Carlos Rossi Alva

Manoel Jerônimo Moreira Cruz

Ana Carina Matos Silva

Maria do Carmo Filardi Barbosa

Flávio Souza Batista

Débora Carol Luz da Porciúncula

Thiago Guimarães Siqueira de Araújo

Gláucio Alã Vasconcelos Moreira
PPG Território, Ambiente e Sociedade (UCSAL), Geoquímica das Interfaces (UFBA).

PPP em Geologia (UFBA), Núcleo de Estudos Hidrogeológicos e do Meio Ambiente (UFBA).

Graduação em Ciências Biológicas (UCSAL)

PPP em Geologia (UFBA), PPG em Geoquímica do Petróleo e Meio Ambiente (UFBA)

Pesquisadora do Grupo Geoquímica das Interfaces (UFBA)

Bióloga da Secretaria Municipal de Sustentabilidade, Inovação e Resiliência (Salvador, Bahia)

Doutorando do PPG em Geologia (UFBA), Grupo Geologia Médica e Geotecnologia Ambiental (UFBA)

PPG Território, Ambiente e Sociedade (UCSAL), Desenvolvimento, Sociedade e Natureza (UCSAL)

Doutorando do PPG Território, Ambiente e Sociedade (UCSAL)

Mestrando do PPG Território, Ambiente e Sociedade (UCSAL) 
Resumo. Esta pesquisa pretendeu investigar a qualidade das águas superficiais costeiras e os teores de metais-traço $(\mathrm{Cu}, \mathrm{Zn}, \mathrm{Cd}$ e $\mathrm{Pb})$ nas folhas da Rhizophora mangle L. na Área de Proteção Ambiental Tinharé-Boipeba, Litoral Sul da Bahia, Brasil. Mensurou-se in situ as variáveis físico-químicas (temperatura, salinidade, $\mathrm{pH}, \mathrm{OD}$ ), com auxílio de sonda multiparâmetros, e tomou-se alíquotas para as análises microbiológicas (NMP) e amostras de folhas da Rhizophora em 10 pontos amostrais para análises biométrica, de diagnose visual e dos metais-traço (F-AAS). Os resultados da quantificação dos coliformes termotolerantes e das análises do OD revelaram alteração da qualidade das águas (70\% dos pontos amostrais), associadas às formas de uso e ocupação do solo e às falhas no saneamento ambiental. A análise de agrupamentos permitiu a classificação das amostras em grupos biogeoquímicos, conforme os teores dos elementos-traço e biometria foliar. Esta análise multivariada sugeriu que a variação na área foliar pode ser explicada, em parte, pelos níveis do Cu e Zn, além de outros fatores ecológicos-ambientais diferentes dos investigados. Os níveis dos metais-traço nas folhas da Rhizophora foram considerados normais e não tóxicos, sendo inferiores aos teores observados em manguezal de áreas impactadas, mas a poluição das águas demanda por gerenciamento costeiro, melhorias no saneamento ambiental e pelo monitoramento da qualidade das águas e dos metais-traço nas folhas de mangue, fauna e nos sedimentos.

Palavras-chave: Gerenciamento Costeiro, Manguezal, Metais-Traço, Saneamento Básico e Ambiental. 


\section{INTRODUÇÃO}

A recente crise ambiental e civilizatória ameaça a reprodução das sociedades globais e da natureza, da qual emerge o dilema entre a conservação ambiental e o crescimento econômico (RUSCHEIMSKY, 2003; AJARA, 2003). Esta crise ambiental descaracteriza os ecossistemas marinhos e costeiros, a julgar pelo manguezal, os quais estão sob crescente pressão da poluição e da rápida urbanização (ZHANG et al., 2014).

Camargo, Capobianco e Oliveira (2004) assinalam que se obteve avanços legais e na adesão da sociedade civil às teses conservacionistas, entretanto pouco se fez após a Conferência Internacional sobre o Meio Ambiente do Rio de Janeiro, a Rio-92. Neste cenário, da emergência da reversão da degradação dos biomas brasileiros frente aos limites biofísicos da economia, desponta-se a relevância da conservação dos bosques de mangue do Baixo Sul da Bahia, Brasil, ecossistema associado ao Bioma Mata Atlântica.

No Litoral Sul da Bahia, no Território de Identidade do Baixo Sul, os impactos ambientais negativos decorrentes do turismo de massas se intensificaram desde 1992, a partir do Programa de Desenvolvimento do Turismo no Nordeste (PRODETUR NE I e II). Neste ano, o poder público criou a Área de Proteção Ambiental (APA) Tinharé-Boipeba pelo Decreto Estadual n.1240, com o objetivo de proteger o ecossistema de Mata Atlântica, e os ecossistemas associados (manguezais e restingas), praias, dunas, recifes de corais e algas coralinas e a geodiversidade, que formam o patrimônio natural. No Litoral Sul da Bahia, o turismo de massas constitui a principal atividade econômica e fonte de renda da população, embora destaque-se entre as atividades degradadoras (SILVA et al., 2007; SILVA et al., 2009). Neste sentido, na APA Tinharé-Boipeba, Lessa (2007), Alencar (2011), Paixão (2015), Paixão, Alencar e Gonçalves (2016), Elliff e Kikuchi (2017), Sant'anna Porto (2019), Pelegrini et al. (2020) indicaram a influência da indústria petrolífera, da sobrepesca e do turismo sobre a biodiversidade, usos da natureza e modos de vida quilombolas, pescador e marisqueiras.

Com isso, ressalta-se que a avaliação ambiental do manguezal na APA Tinharé-Boipeba contribui para o desenvolvimento social, usos da natureza e à manutenção dos serviços ecossistêmicos. Estes serviços equivalem às condições em que os ecossistemas naturais, e as espécies que o compõem, sustentam a vida, a economia, a sociedade e o bem-estar social (DAILY, 1997; HOLMLUND; HAMMER, 1999; BARBAUT, 2011). 
A conservação do manguezal permite o fornecimento de serviços ecossistêmicos fundamentais ao bem-estar humano (BRANDER et al., 2012; ANNEBOINA; KUMAR, 2017; MARTUTI; WIDIANARKO e YULIANTO, 2017; ALEMU et al., 2021). Estes serviços ofertados contemplam a proteção da linha de costa, abrigo para os organismos, em especial das formas juvenis, a exportação de nutrientes, os estoques pesqueiros, sequestro de carbono, para as práticas educativas, recreativas, alimentação, setores de energia e transporte e retenção de poluentes pela rizosfera e pelos sedimentos.

Neste recorte, destaca-se que a poluição por metais-traço ameaça a saúde humana e a oferta dos serviços dos ecossistemas costeiros (ABOU SEEDO et al., 2017). Jesus et al. (2004) assinalaram que a poluição das áreas costeiras, e do manguezal, por metais-traço associam-se à perda de qualidade ambiental. Assim, esta pesquisa almejou investigar a qualidade das águas superficiais costeiras e os teores de metais-traço ( $\mathrm{Cu}, \mathrm{Zn}, \mathrm{Cd}$ e $\mathrm{Pb}$ ) nas folhas de mangue na APA Tinharé-Boipeba, Litoral Sul da Bahia.

\section{MATERIAIS E MÉTODOS}

\subsection{DESCRIÇÃO DA ÁREA DE ESTUDO}

Esta pesquisa realizou-se na Área de Proteção Ambiental (APA) Tinharé-Boipeba, pertencente ao município de Cairu, no Litoral Sul da Bahia (Figura 1). Cairu possui uma população de 15.374 habitantes, Produto Interno Bruto de 1.397.356,00 mil reais e Índice de Desenvolvimento Humano Municipal - IDM de 0,627 (IBGE, 2010).

A APA Tinharé-Boipeba apresenta uma área total de 43.000 hectares, clima quente e úmido, tropical costeiro. A temperatura média anual é de $24,6^{\circ} \mathrm{C}$, com valores máximos de $31,2^{\circ} \mathrm{C}$ (março) a $27,6^{\circ} \mathrm{C}$ (julho), mínimos de $24,4^{\circ} \mathrm{C}$ (março) a $19,4^{\circ} \mathrm{C}$ (agosto). Apresenta pluviometria média anual de $2.118,7$ mm, cujas chuvas concentram-se de março a agosto, e umidade relativa de 80 a 90\% (BRASIL, 1995; SEI, 2014). 
Figura 1. Mapa de localização, situação e espacialização dos pontos de coleta de águas superficiais

(E1 a E11) nas Ilha de Tinharé-Boipeba, Litoral Sul da Bahia, Brasil.

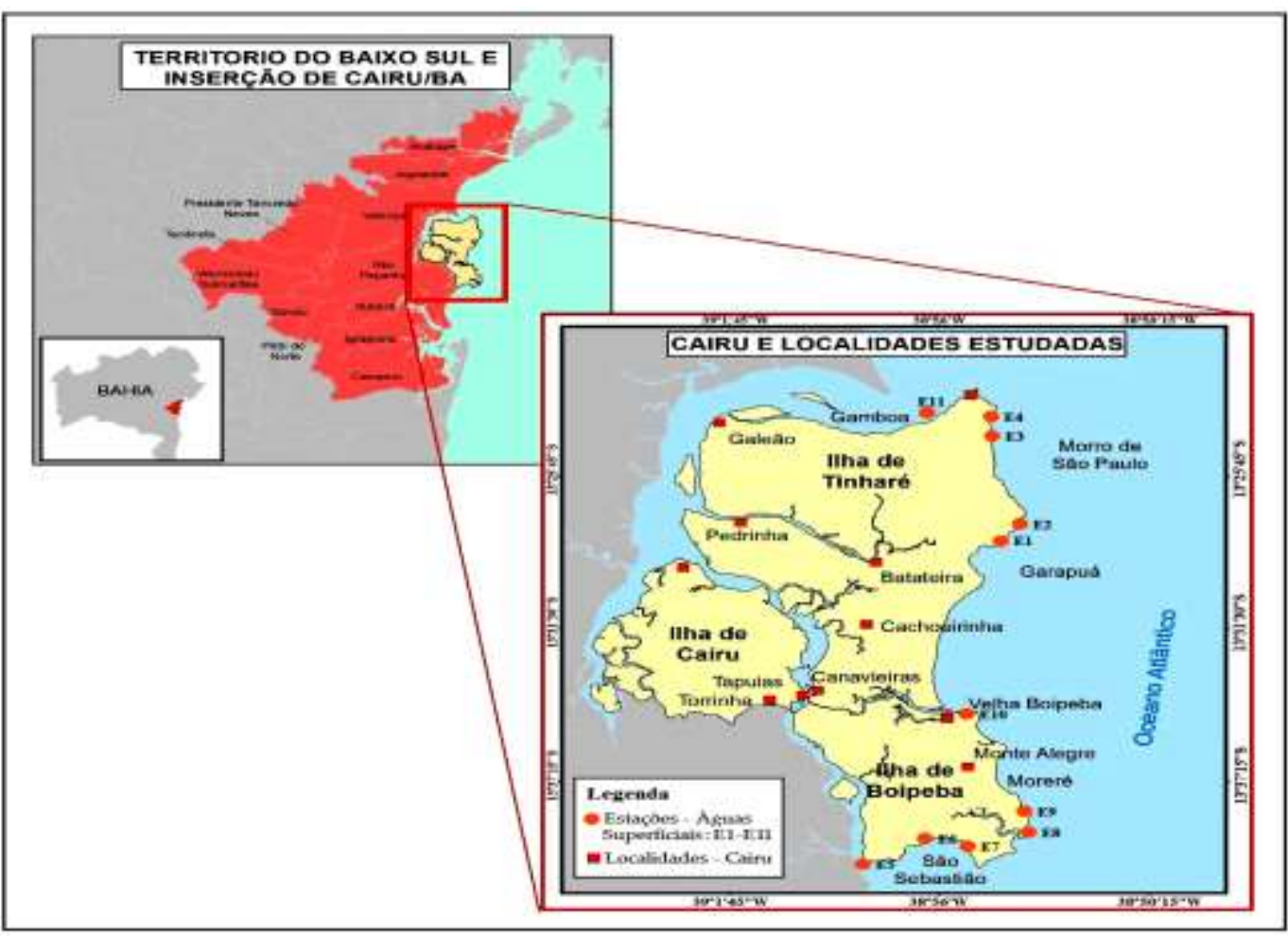

Fonte: Modificado de Paixão (2015).

Na geologia local afloram as rochas sedimentares areníticas, carbonáticas e os folhelhos (Cenozóico ou Mesozóico) da Bacia de Camamu, depositados sobre o embasamento cristalino gnáissico (BARBOSA; DOMINGUEZ, 1996). Esta Bacia tem relevância hidrogeológica e hospeda minérios nãoenergéticos (barita), óleo e gás nos arenitos, rochas-reservatórios, selados por folhelhos da Formação Sergi. Outrossim, destacam-se na geodiversidade, dentre as referências paisagísticas e patrimônio natural, que constituem os atrativos ao turismo na APA Tinharé-Boipeba, os terraços arenosos marinhos holocênicos e pleistocênicos, os depósitos de mangue, as áreas úmidas, as falésias de litofácies areníticas ou carbonáticas, as enseadas e os promontórios rochosos.

O arquipélago Tinharé-Boipeba, que contempla a APA, é constituído por um modelado plano a suave ondulado e forte ondulado, que abrange as unidades Baixada Litorânea e Planícies Marinhas e FlúvioMarinhas. Esta última unidade revela enorme diversidade de feições relevantes aos usos e ocupação do solo devido à forte interação entre processos geológicos e sócio-espaciais. Nesse modelado, distribui-se uma rede hidrográfica densa e dendrítica caracterizada por seus rios de primeira a terceira ordens, sendo a maioria perene, cujos rios mais importantes têm influência da dinâmica do Oceano e das marés. 
A ecologia da paisagem da APA Tinharé-Boipeba caracteriza-se pela presença de fitofisionomias diversas relacionadas ao complexo de ecossistemas do Bioma Mata Atlântica, como restinga, manguezal e os fragmentos remanescentes da floresta Atlântica, além dos ecossistemas praial, áreas úmidas e à vegetação descaracterizada (antropizada). Estas fitofisionomias ocorrem bordejadas pelos recifes de corais e algas coralinas e bosques de mangue. Estes destacam-se no distrito de Garapuá, na ilha de Tinharé, embora ganham relevância na ilha de Boipeba, quase completamente bordejada pelos bosques de mangue.

\subsection{CARACTERIZAÇÃO DAS ÁGUAS SUPERFICIAIS}

A caracterização das águas superficiais foi realizada a partir de uma rede de 10 estações amostrais na APA Tinharé-Boipeba (Figura 1). Em cada estação, posicionada com auxílio de um GPS (Global Positioning System), mensurou-se in situ as variáveis físico-químicas (temperatura, salinidade, $\mathrm{pH}$, OD), com auxílio de sonda multiparâmetros. Tomou-se, igualmente, alíquotas para as análises de coliformes de água superficial na linha de costa, na baixa-mar, na ilha de Tinharé, utilizando-se coletores plásticos estéreis, dispostos contra a corrente, contendo tiossulfato de sódio. Estas alíquotas seguiram refrigeradas em caixa de isopor com gelo para o Laboratório de Estudos em Meio Ambiente (LEMA), da Universidade Católica do Salvador (UCSAL), para a realização das análises de microbiológicas conforme as orientações da APHA (2005).

Adotou-se a quantificação dos coliformes com auxílio da técnica do número mais provável (NMP) em $100 \mathrm{~mL}$, a partir do caldo Lauril Sulfato Triptose (LST, Acumedia) no teste presuntivo (incubação a 35 ${ }^{\circ} \mathrm{C} / 48$ h). Usou-se o caldo Lactosado Bile Verde Brilhante (LBVB, Acumedia) na quantificação de coliformes totais (incubação a $35^{\circ} \mathrm{C} / 48 \mathrm{~h}$ ) e o caldo Escherichia coli (EC, Acumedia) na quantificação dos coliformes termotolerantes (incubação a $44,5^{\circ} \mathrm{C} / 24 \mathrm{~h}$ em banho-maria) por amostra.

\subsection{DIAGNOSE, BIOMETRIA E METAIS-TRAÇO EM FOLHAS DE MANGUE}

Realizou-se com a coleta de folhas da Rhizophora mangle L. (Rhizophoraceae), a partir da distribuição das áreas de mangue em franja ou de transição nas ilhas de Tinharé (E1-E4) e Boipeba (E5-E10) (Figura 1), usando-se um GPS (Global Positioning System). Obteve-se, aleatoriamente, duas parcelas de $10 \mathrm{~m}^{2}$ em cada ponto de coleta de 30 folhas adultas, a partir do terceiro nó, na extremidade distal do ramo, dispostas em sacos plásticos identificados e refrigeradas à uma temperatura de aproximadamente $4^{\circ}$ C. 
Enviou-se as folhas $R$. mangle coletadas nos pontos amostrais para as análises da integridade foliar, biometria e metais-traço ( $\mathrm{Cu}, \mathrm{Cd}, \mathrm{Pb}, \mathrm{Zn})$. Iniciou-se a análise da integridade foliar, pela diagnose visual, in loco, cujas informações foram registradas na caderneta de campo, sendo a diagnose foliar revisitada, junto com a biometria foliar, no LEMA (UCSAL). Abrangeu a presença de galhas, perfurações (e recortes), pastejo (herbivoria), clorose (despigmentação), necrose (morte celular) e manchas escuras. Usou-se um paquímetro manual nas aferições biométricas (comprimento e largura).

Realizou-se a leitura dos metais-traço nas folhas de mangue por Espectrometria de Absorção Atômica com Chama (F-AAS) (Varian Spectr AA-6440Z), em duplicatas, com 20\% de triplicatas, após a adição de $3 \mathrm{ml}$ de $\mathrm{HNO}_{3}(1: 1)$ a uma massa de $0,5 \mathrm{~g}$ de amostra (peso seco) e abertura em forno de micro-ondas. Os analitos foram lidos em duplicatas, mais brancos e um padrão de referência internacional (National Institute of Standards and Technology, Apple Leaves - NIST-1515), pela parceria LEMA (UCSAL) e o Núcleo de Estudos Ambientais (NEA) da Universidade Federal da Bahia (UFBA). A Tabela 1 mostra as condições de detecção dos metais-traço e do controle de qualidade analítica, cuja recuperação variou de $60 \%$ a $103 \%$ nos metais-traço, sendo maior no $\mathrm{Zn}$.

Tabela 1. Avaliação da recuperação de abertura de metais-traços em amostras de folhas de $R$. mangle em forno de micro-ondas, a partir do uso do padrão de referência internacional NIST-1515.

\begin{tabular}{ccccc}
\hline Padrão (NIST-1515) & $\mathbf{C u}\left(\boldsymbol{\mu g} \cdot \mathbf{g}^{-\mathbf{1}}\right)$ & $\mathbf{C d}\left(\boldsymbol{\mu g} . \mathbf{g}^{-\mathbf{1}}\right)$ & $\mathbf{P b}_{\left(\boldsymbol{\mu g} . \mathbf{g}^{-\mathbf{1}}\right)}$ & $\mathbf{Z n}\left(\boldsymbol{\mu g} \cdot \mathbf{g}^{-\mathbf{1}}\right)$ \\
\hline $\boldsymbol{\lambda}(\mathbf{n m})$ & 324.80 & 228.80 & 217.00 & 213.90 \\
NIST 1515 & 5.64 & 0.002 & 0.47 & 12.50 \\
Padrão (média do valor encontrado) & 3.87 & 0.001 & 0.35 & 12.92 \\
Recuperação (\%) & 70.00 & 60.00 & 74.00 & 103.00 \\
Limite de detecção & 0.019 & 0.015 & 0.0133 & 0.012 \\
\hline
\end{tabular}

\subsection{FATOR DE CONCENTRAÇÃO}

Obteve-se o Fator de Concentração (FC) a partir da razão entre as concentrações do metal na folha e do metal-traço presente no substrato. Na APA Tinharé-Boipeba, calculou-se o FC com base nos teores de metais-traço do folhelho padrão, de acordo com Turekian e Wedepohl (1961), ou tomando-se como base os teores de metais-traço dos sedimentos da zona estuarina da Baía de Camamu, conforme Oliveira et al. (2009).

\subsection{ANÁLISE ESTATÍSTICA}

Adotou-se na análise estatística abordagens descritiva e inferencial, testes de normalidade (ShapiroWilk), testes de comparações múltiplas usados para dados paramétricos (One-Way - ANOVA), ou para 
dados não-paramétricos (Kruskal-Wallis), com nível de confiança de 95\%, e a Análise de Agrupamento (cluster analysis), pautada na distância Euclidiana e no método de Ward na análise da ligação entre os grupos.

\section{RESULTADOS E DISCUSSÃO}

\subsection{DESCRIÇÃO DOS PONTOS AMOSTRAIS E ASPECTOS ECOLÓGICOS-SÓCIO-AMBIENTAIS}

Obteve-se um sumário estatístico descritivo das condições sócio-ambientais e suas relações com indicadores de saneamento e de saúde na nos municípios costeiros que configuram o Território de Identidade do Baixo Sul, no Estado da Bahia (Tabela 1).

Tabela 1. Domicílios particulares permanentes dos domicílios com serviço de saneamento e indicação de internações por diarreia de municípios do Baixo Sul da Bahia - 2010, de acordo com o IBGE 2010.

\begin{tabular}{|c|c|c|c|c|c|c|c|c|}
\hline \multirow[b]{2}{*}{ Município } & \multicolumn{2}{|c|}{ População } & \multirow{2}{*}{$\begin{array}{l}\text { Densidade } \\
\left(\text { hab.km²) }^{2}\right.\end{array}$} & \multicolumn{3}{|c|}{ IDH-M } & \multirow{2}{*}{$\begin{array}{c}\text { Esgotamento } \\
\text { Sanitário } \\
\text { Adequado (\%) }\end{array}$} & \multirow[b]{2}{*}{$\begin{array}{c}\text { Internações por diarreia por mil } \\
\text { habitantes }\end{array}$} \\
\hline & 2010 & $\begin{array}{c}\mathbf{2 0 2 0} \\
\text { (estimada) }\end{array}$ & & 1991 & 2000 & 2010 & & \\
\hline Cairu & 15.374 & 18.427 & 33.35 & 0.259 & 0.437 & 0.627 & 44.80 & 1.50 \\
\hline Camamu & 35.180 & 35.382 & 38.22 & 0.270 & 0.377 & 0.565 & 31.20 & 0.50 \\
\hline Nilo Peçanha & 12.530 & 14.079 & 31.38 & 0.236 & 0.384 & 0.584 & 31.50 & 0.80 \\
\hline Taperoá & 18.748 & 21.253 & 45.64 & 0.265 & 0.381 & 0.566 & 25.70 & 3.20 \\
\hline Valença & 88.673 & 97.233 & 74.35 & 0.376 & 0.486 & 0.623 & 59.50 & 1.80 \\
\hline \multicolumn{9}{|l|}{$\begin{array}{l}\text { Estimadores } \\
\text { Amostrais }\end{array}$} \\
\hline Mínimo & 12.53 & 14.08 & 31.38 & 0.236 & 0.377 & 0.565 & 25.70 & 0.50 \\
\hline Máximo & 88.67 & 97.23 & 74.35 & 0.376 & 0.486 & 0.627 & 59.50 & 3.20 \\
\hline Média & 34.10 & 37.27 & 44.59 & 0.281 & 0.413 & 0.593 & 38.54 & 1.56 \\
\hline Mediana & 18.75 & 21.25 & 38.22 & 0.265 & 0.384 & 0.584 & 31.50 & 1.50 \\
\hline Desvio Padrão & 31.75 & 34.45 & 17.52 & 0.05 & 0.05 & 0.03 & 13.66 & 1.05 \\
\hline Erro Padrão & 14.20 & 15.41 & 7.84 & 0.02 & 0.02 & 0.01 & 6.11 & 0.47 \\
\hline $\mathrm{CV}(\%)$ & 93.09 & 92.43 & 39.30 & 19.41 & 11.53 & 5.09 & 35.45 & 67.63 \\
\hline$S W($ valor de $p)$ & 0.038 & 0.025 & 0.096 & 0.044 & 0.107 & 0.134 & 0.346 & 0.603 \\
\hline
\end{tabular}

CV: coeficiente de variação; SW: Shapiro-Wilker; ${ }^{a}$ distribuição gaussiana; ${ }^{b}$ distribuição não gaussiana. Fonte: Elaborado pelos autores, a partir do Censo Demográfico de 2010 (IBGE, 2010).

Verificou-se que os valores do Índice de Desenvolvimento Humano Municipal (IDH-M) foram classificados de baixo a médio, com tendência de melhora desde 1991, nos municípios costeiros do Baixo Sul da Bahia, conforme o IBGE (2010) (Tabela 1). Estes municípios demandam empenho do poder público e da sociedade na melhoria da qualidade da educação, da distribuição de renda e da expectativa de vida ao nascer neste território. Outrossim, os valores do IDM-M de 2010 dos municípios do Baixo Sul foram menores que quando comparado ao IDH-M de Salvador $(0,660)$, ou da Bahia $(0,759)$. 
Predominaram uma cobertura de esgotamento sanitário adequado inferior a $50 \%$ nos municípios do Baixo Sul, com maior cobertura no município de Valença (Tabela 1). Outrossim, observou-se, com bases nas informações do Censo do IBGE (2010) e do IBGE (2019), que os valores da cobertura do esgotamento adequado sanitário nestes municípios foram, no geral, inferiores aos valores do município de Salvador (92.8\%), ou dos valores médios obtidos para o Estado da Bahia (46\%), ou para o Brasil (75\%).

Ressalta-se não ser evidente a relação entre o esgotamento sanitário e o índice de internações por diarreia por mil habitantes no Baixo Sul da Bahia (Tabela 1). Obteve-se a situação mais grave deste indicador de saúde nos municípios de Taperoá, Valença e Cairu, que talvez decorra dos usos e da ocupação do solo e de subnotificação dos dados. Gonçalves et al. (2021) e Batista et al. (2021) encontraram uma relação inversa entre a cobertura do esgotamento e o índice de internações por diarreia por mil habitantes nos municípios da Região Metropolitana de Salvador e do Oeste do Estado da Bahia.

Segue-se com a análise das condições sócio-ambientais e suas relações com o saneamento e a saúde nas localidades da APA Tinharé-Boipeba (Quadro 1). Observa-se, na pesquisa de campo, que as espécies de mangue sobre diversos substratos, corte de árvores de mangue na Praia do Encanto (E2), haver evidencias da erosão marinha, como árvores caídas e raízes de coqueiros expostas, a presença de barracas de alvenaria na face da praia, e outras formas de ocupação da linha de costa, despejos inapropriados de efluentes líquidos e de resíduos sólidos (garrafas pet, sacos plásticos e isopor), na praia.

No município de Cairu, a disposição final dos resíduos sólidos ("lixo") nos vazadouros a céu aberto (“lixões”), em desacordo com a Lei no 12.305/10 (BRASIL, 2010), que estabelece a Política Nacional de Resíduos Sólidos, aflige os distritos de Cairu, Velha Boipeba (Moreré) e Gamboa (Morro de São Paulo). A coleta, o transporte e a disposição final do "lixo" desafiam, especialmente, o gestor público, e a sociedade, na localidade de Morro de São Paulo, a qual representa um importante destino turístico.

Estes aspectos sócio-ambientais demandam pela perspectiva do saneamento ambiental e por uma gestão ambiental costeira sensível às tensões e aos conflitos sócio-ambientais pelos usos da natureza. Entende-se que as tensões e os conflitos sócio-ambientais emergem da questão de uns grupos sociais se beneficiarem mais, enquanto que outros grupos pagam um maior custo sócio-ambiental (MARTINEZ-ALIER, 2004). 
Compreende-se que os conflitos e as tensões associados aos usos da natureza emergem de rupturas do acordo simbólico entre as diferentes práticas sociais no espaço de apropriação material e simbólica dos recursos do território (ASCSELRAD, 2004). Nesta perspectiva, os conflitos e as tensões sócioambientais emergem no território, sob determinadas relações de poder, a partir de rupturas de acordos materiais e simbólicos. Santos (2007) compreende o território como o lugar da residência, que contempla uma complexa rede de trocas materiais e espirituais e a realização do trabalho e da vida.

Quadro 1. Características ecológico-geoambientais das estações amostrais da APA Tinharé-Boipeba.

\begin{tabular}{|c|c|c|c|}
\hline Estação & Localidade & Coordenada (UTM) & $\begin{array}{l}\text { Características e Impactos Ecológico- } \\
\text { Geoambientais }\end{array}$ \\
\hline E1 & $\begin{array}{l}\text { Praia do } \\
\text { Encanto a }\end{array}$ & 8515242 & $\begin{array}{l}\text { Vegetação sobre substrato arenoso rico } \\
\text { em bioclasto, domínio da } R \text {. mangle, } \\
\text { altura relativa de } \pm 6 \text { m; canal de maré } \\
\text { com pequeno aporte fluvial; presença de } \\
\text { Crassostrea rhizophorae (Guilding, 1828) } \\
\text { (ostra-de-mangue) sobre rizóforos; } \\
\text { Littoraria angulifera (Lamarck, 1822) (faz } \\
\text { perfurações foliares); presença de sacos } \\
\text { plásticos e garrafas pet. }\end{array}$ \\
\hline E2 & $\begin{array}{l}\text { Praia do } \\
\text { Encanto a }^{a}\end{array}$ & 8516142 & $\begin{array}{l}\text { Vegetação sobre substrato fino lamoso } \\
\text { ou arenoso, domínio da } R \text {. mangle com } \\
\text { altura relativa de } 4 \text { a } \mathbf{1 0} \text { m ( } \pm 6 \text { m), } \\
\text { rizóforos desenvolvidos e serapilheira; L. } \\
\text { angulifera; vestígios de corte de árvores; } \\
\text { resíduos sólidos recalcitrantes (isopor, } \\
\text { sacos plásticos, garrafas pet) neste trecho } \\
\text { de praia pouco habitada e de difícil } \\
\text { acesso na preamar. }\end{array}$ \\
\hline E3 & 4a Praia ${ }^{a}$ & 8520104 & $\begin{array}{l}\text { Vegetação sobre arenito, substrato } \\
\text { arenoso, ou recifes pétreos, domínio da }\end{array}$ \\
\hline
\end{tabular}




\begin{tabular}{|c|c|c|c|c|}
\hline & & & & $\begin{array}{l}\text { L. racemosa, altura de } \pm \mathbf{3} \text { m da } R \text {. } \\
\text { mangle; ocupação da praia por barracas } \\
\text { protegidas com estacas de coqueiro, } \\
\text { algumas com alicerces de alvenaria } \\
\text { contra a erosão marinha; fluxo de turistas } \\
\text { e uso recreacional das piscinas nos } \\
\text { recifes pétreos na baixa mar; riacho que } \\
\text { corta a praia, na interface com a 3a Praia, } \\
\text { próximo às piscinas dos recifes. }\end{array}$ \\
\hline E4 & 2a Praia ${ }^{\text {a }}$ & 509273 & 8520884 & $\begin{array}{l}\text { Vegetação sobre arenito da Fm. } \\
\text { Camamu, substrato lamoso-arenoso, ou } \\
\text { sobre recifes, domínio da L. racemosa; } R \text {. } \\
\text { mangle de } \pm 4 \text { m; barracas de alvenaria } \\
\text { na face da praia (contra a erosão } \\
\text { marinha); turistas; pós-praia limitado por } \\
\text { falésias de arenito; isopor, embalagem de } \\
\text { cigarros, sacos plásticos, garrafas pet; } \\
\text { riacho fétido de água de cor escura que } \\
\text { corta a praia, na interface com a 3a Praia, } \\
\text { próximo às piscinas dos recifes. }\end{array}$ \\
\hline E5 & $\begin{array}{c}\text { Ilha do Rato } \\
\text { b }\end{array}$ & 5033797 & 8488164 & $\begin{array}{l}\text { Ilhota próxima a foz do rio Bainema, } \\
\text { bordejada de mangue sobre substrato } \\
\text { arenoso-lamoso, altura de } \mathbf{\pm} \mathbf{3} \text { m; pastejo, } \\
\text { galhas e perfurações; presença de } L \text {. } \\
\text { angulifera; resíduos sólidos recalcitrantes } \\
\text { (sacos plásticos, garrafas pet) e fluxo de } \\
\text { lanchas rápidas. }\end{array}$ \\
\hline E6 & $\begin{array}{c}\text { São } \\
\text { Sebastião b }\end{array}$ & 505833 & 8489440 & $\begin{array}{l}\text { Pequena baía, vegetação sobre } \\
\text { substratos arenoso ou arenoso-lamoso } \\
\text { cinza, fétido, altura de } \pm \mathbf{5} \text { m; resíduos de }\end{array}$ \\
\hline
\end{tabular}




\begin{tabular}{|c|c|c|c|c|}
\hline & & & & $\begin{array}{c}\text { mariscagem, mancha de óleo, despejos } \\
\text { de esgotos ao mar. }\end{array}$ \\
\hline E7 & $\begin{array}{c}\text { Ponta dos } \\
\text { Castelhano } \\
\text { b }\end{array}$ & 508930 & 8488324 & $\begin{array}{l}\text { Situa-se próximo ao do rio Catu; } \\
\text { vegetação sobre substrato arenoso, com } \\
\text { domínio da } R \text {. mangle, altura de } \pm 6 \mathrm{~m} ; C \text {. } \\
\text { rhizophorae sobre rizóforos bem } \\
\text { desenvolvidos da } R \text {. mangle; alterações } \\
\text { foliares (necrose, clorose e perfurações); } \\
\text { caramujo L. angulifera. }\end{array}$ \\
\hline E8 & Moreré I b & 511260 & 8492542 & $\begin{array}{l}\text { Situa-se próximo ao rio Catu; vegetação } \\
\text { sobre substrato arenoso; com domínio da } \\
\text { R. mangle, altura de } \mathbf{1 0} \text { a } \mathbf{2 0} \text { m, presença } \\
\text { de propágulos desta espécie; e uso } \\
\text { recreacional das piscinas nos recifes na } \\
\text { baixa mar; resíduos sólidos acumulados } \\
\text { na baixa-mar. }\end{array}$ \\
\hline E9 & Moreré II ${ }^{b}$ & 510073 & 8495132 & $\begin{array}{l}\text { Situa-se na foz do rio Bainema; vegetação } \\
\text { arbustiva-arbórea sobre substrato } \\
\text { arenoso; com } \pm \mathbf{5} \text { m; sacos plásticos } \\
\text { presos aos rizóforos; perfurações } \\
\text { foliares; L. angulifera. }\end{array}$ \\
\hline E10 & Cueira b & 510033 & 8496782 & $\begin{array}{l}\text { Situa-se na foz do rio Santo; vegetação } \\
\text { heterogênea sobre substrato arenoso; } \\
\text { altura de } \mathbf{\pm} \mathbf{2} \text { m; destacaram-se as } \\
\text { manchas escuras e perfurações nas } \\
\text { folhas de mangue. }\end{array}$ \\
\hline
\end{tabular}

${ }^{a}$ Morro de São Paulo, pertencente ao distrito de Gamboa; ${ }^{b}$ pertencem ao distrito Velha Boipeba.

Neste recorte, a Tabela 2 apresenta os aspectos sócio-ambientais a partir da síntese dos dados do saneamento básico, com base nos dados do IBGE (2010), das localidades de Gamboa, Garapuá, Moreré e São Sebastião, município de Cairu, Bahia. Tem-se que a abrangência da coleta e a disposição 
final dos resíduos sólidos ("lixo") foram similares entre os distritos, destacando-se o serviço de limpeza municipal. Outrossim, a cobertura do abastecimento de água, realizada pela Empresa Baiana de Águas e Saneamento S.A. (EMBASA), abrange as localidades de Gamboa, Garapuá e São Sebastião, ao passo que se observa falhas na cobertura do esgotamento sanitário adequado, que representa risco de poluição do solo, das águas e à saúde da população.

Tabela 2. Síntese dos dados de saneamento básico do IBGE (2010) para o município de Cairu, Bahia.

\begin{tabular}{|c|c|c|c|c|c|}
\hline Aspectos do Saneamento & Gamboa* & Garapuá* & Moreré* & São Sebastião* & $\begin{array}{c}\text { Morro de } \\
\text { São Paulo* }\end{array}$ \\
\hline \multicolumn{6}{|l|}{1 Abastecimento de Água } \\
\hline 1.1 Rede Geral da EMBASA & 810 & 156 & 4 & 202 & 1.425 \\
\hline 1.2 Poço ou nascente (particular) & 10 & - & 19 & 10 & - \\
\hline 1.3 Outra (águas pluviais, carro-pipa, etc.) & 38 & 5 & 46 & 8 & 133 \\
\hline \multicolumn{6}{|l|}{2 Esgotamento Sanitário } \\
\hline 2.1 Rede Geral ou pluvial da EMBASA & 6 & - & - & 3 & 1.503 \\
\hline 2.2 Via Fossa Séptica & 110 & - & 60 & 194 & 50 \\
\hline 2.3 Fossa Rudimentar (negra, poço, buraco, etc) & 402 & 154 & 2 & 3 & 5 \\
\hline 2.4 Via vala & 8 & - & - & - & - \\
\hline 2.5 Via lago, rio, mar & 310 & - & - & - & - \\
\hline 2.6 Outro escoadouro & 22 & 7 & 1 & 20 & - \\
\hline \multicolumn{6}{|l|}{3 Coleta e Destinação do Lixo } \\
\hline 3.1 Serviço de Limpeza & 852 & 160 & 51 & 204 & 1.526 \\
\hline 3.2 Caçamba de Serviço de Limpeza & 5 & - & 16 & - & - \\
\hline 3.3 Queimado na propriedade & 1 & 1 & 1 & 16 & 2 \\
\hline 3.4 Enterrado na propriedade & - & - & 1 & - & - \\
\hline 4 Distrito & Gamboa & Garapuá & Velha Boipeba & Velha Boipeba & Gamboa \\
\hline 4.1 Número de Habitantes & 2.736 & 587 & 254 & 729 & 4.501 \\
\hline 4.2 Número de Domicílios & 858 & 161 & 69 & 220 & 1.558 \\
\hline
\end{tabular}

Fonte: Elaborado pelos autores a partir do IBGE (2010). *Equivale unidade domiciliar (DU).

Desvela-se na localidade de Garapuá, que a maior parte dos domicílios são abastecidos pela rede geral de água, mas a população não dispõe de esgotamento sanitário adequado, e que 154 domicílios usam as fossas rudimentares (Tabela 2). Outrossim, lava-se roupas e lança-se os efluentes líquidos in natura na lagoa homônima, promovendo-se tensões pelo uso da água, atingindo-se a recreação, atrativo ao turismo, ou até mananciais e o abastecimento. Porciúncula, Alencar e Gonçalves (2021) assinalam que a tensão representa uma categoria de análise que acolhe as contradições, cujas tensões pelo uso da água refletem como os processos sócio-espaciais se apropriam da água e atingem os usos da natureza e os modos de vida.

Ressalta-se que a localidade de Morro de São Paulo, na Ilha de Tinharé, com 1.558 habitantes, conta com um sistema de esgotamento sanitário, desde de 2002, de responsabilidade da EMBASA, mas possui, com base no censo do IGBE (2010), uma rede geral ou pluvial que contempla $96 \%$ dos domicílios (Tabela 2). Contudo, de acordo com o Plano de Manejo da APA Tinharé-Boipeba, e dados de campo, as residências e os equipamentos na beira dos rios nos distritos de Cairu, Galeão, São Sebastião e Velha Boipeba lançam seus efluentes líquidos in natura nos rios, lagos, estuário ou no mar. 
Em relação a localidade de Moreré, com base nos dados do IBGE (2010), não conta com sistema de esgotamento sanitário, utiliza-se fossas sépticas, e a maioria dos domicílios não está ligada a rede de água, o que demanda aos moradores a buscarem fontes naturais locais para o abastecimento, mesmo que se desconheça a sua qualidade.

Vilar et al. (2021) realizaram um estudo epidemiológico, descritivo e transversal, não probabilístico em 105 moradores da llha de Boipeba, no Baixo Sul da Bahia, efetuaram exame parasitológico e aplicaram questionário do perfil sociodemográfico. Encontraram relatos de sintomas gastrointestinais em 82,8\% dos participantes e uma prevalência de infecções enteroparasitárias de 69,9\%, destacandose, dentre os parasitas, os Ancilostomídeo (18,1\%) e Entamoeba coli $(43,8 \%)$. Todos participantes do estudo possuíam água encanada, embora não tratada, 91,4\% declararam ingerir vegetais crus e 45,7\% não higienizavam as mãos antes da refeição. Os autores concluíram que talvez os hábitos precários de higiene e de acesso à água tratada, relacionados às condições sócio-ambientais e climáticas locais, contribuam para a elevada prevalência de geohelmintos.

Neste contexto, as falhas no esgotamento sanitário ameaçam os usos da água e à saúde da população dos municípios costeiros do Baixo Sul da Bahia, e demandam por políticas públicas de saneamento, educação e saúde, em especial nas áreas periféricas. Outrossim, os investimentos em saneamento, na educação e políticas de redução das assimetrias sociais podem reduzir gastos com saúde e mortes evitáveis desta população.

Teixeira e Pungirum (2005), Bellido et al. (2010) e Buhler et al. (2014) e Gonçalves et al. (2021) destacam a relevância das relações entre saneamento e ambiente no estudo dos problemas de saúde pública, como das doenças de veiculação hídricas. Rasella (2013), Paiva (2018), Kuiava et al. (2019) e Nascimento (2019) assinalam que no Brasil o perfil de saneamento, principalmente do esgotamento sanitário, pode ser relacionado às proporções de morbidade e de mortalidade infantil por diarreias.

\subsection{CLASSIFICAÇÃO DAS ÁGUAS E QUALIDADE AMBIENTAL}

Obteve-se valores da temperatura das águas da APA de Tinharé-Boipeba entre 27,7 a 31 oC e salinidade de 36,6 a 37 PSU, sendo, por isso, classificadas como Águas Salinas Classes 1 e 2 (Tabela 3), com base na Resolução Conama no 357/2005 (BRASIL, 2005). Esses valores da salinidade das águas nos pontos amostrais refletem a influência do ar e da massa de Água Tropical, e da Corrente do Brasil, identificadas pelos valores da salinidade que excedem a 36,9 PSU e temperaturas entre 22 e 28 ㅇ. 
Tabela 3. Sumário estatístico das variáveis físico-químicas nas águas superficiais da APA TinharéBoipeba.

\begin{tabular}{|c|c|c|c|c|}
\hline Estimador Amostral & Salinidade (PSU) & Temp. $\left({ }^{\circ} \mathrm{C}\right)$ & pH & OD (mg.L $\left.{ }^{-1}\right)$ \\
\hline Mínimo & 34.00 & 27.20 & 7.20 & 1.14 \\
\hline Máximo & 36.90 & 31.60 & 8.20 & 6.17 \\
\hline Média & 36.10 & 30.09 & 7.66 & 4.11 \\
\hline Mediana & 36.20 & 30.65 & 7.63 & 3.89 \\
\hline Erro Padrão & 0.26 & 0.44 & 0.11 & 0.47 \\
\hline Desvio Padrão & 0.82 & 1.38 & 0.34 & 1.50 \\
\hline Coeficiente de Correlação (\%) & 2.26 & 4.57 & 4.42 & 36.37 \\
\hline Shapiro-Wilker (valor de p) & $0.007^{\mathrm{B}}$ & $0.61^{\mathrm{A}}$ & $0.11^{\mathrm{A}}$ & $0.28^{\mathrm{A}}$ \\
\hline $\begin{array}{c}\text { CONAMA 357/2005 } \\
\text { (Águas Salobras - Classe 1) }\end{array}$ & $6.5-8.5$ & - & $0.5-30.0$ & $>6.0$ \\
\hline $\begin{array}{c}\text { CONAMA 357/2005 } \\
\text { (Águas Salinas - Classe 1) }\end{array}$ & $6.5-8.5$ & - & $\geq 30.0$ & $>5.0$ \\
\hline
\end{tabular}

Fonte: Autores, 2021.

As condições alcalinas das amostras foram relacionadas à influência das águas marinhas, com os maiores valores do pH na foz dos rios Catu (E7-E8) e Bainema (E9) (Tabela 3). Nas condições de pH das amostras de águas da APA, os íons metálicos tendem a ser precipitados como hidróxidos e adsorvidos aos argilominerais no material particulado em suspensão, com base no que propõem Chapman e Wang (2001). O pH da solução têm relevância para a adsorção de íons metálicos, porque interfere nos sítios ativos do material adsorvente e na especiação dos íons em solução (OZER et al., 2004).

Nurchi e Villaescusa (2008) compreendem que os valores do pH influenciam os fenômenos da hidrólise, complexação por ligantes orgânicos ou inorgânicos, reações redox e de precipitação. Estes fenômenos afetam a disponibilidade e a adsorção dos íons metálicos nos reservatórios biogeoquímicos dos ecossistemas e na qualidade ambiental. Desta forma, espera-se a influência da matriz salina, da matéria orgânica e do pH do meio na complexação dos metais-traço, na distribuição das espécies químicas presentes, nos teores de metais-traço dissolvidos na água, adsorvidos nos materiais minerais em suspensão, ou precipitados, ou dos níveis de metais-traços presentes nos sedimentos.

Os níveis do OD variaram de 1,1 a 6,2 mg. $\mathrm{L}^{-1}$ (Tabela 3), com 70\% das amostras em desacordo com a Resolução 357/05 do CONAMA (BRASIL, 2005) para as águas salinas da Classe 1 (Figura 2). Obteve-se o menor nível do OD na 4ํ Praia, Morro de São Paulo (E3), relevante destino turístico (Figura 2). Os níveis de OD das amostras foram inferiores aos das águas estuarinas e costeiras de Garapuá, Barra dos Carvalhos, Canal de Taperoá e dos rios Graciosa, Una, Pardo e Jequitinhonha, no Litoral Sul Bahia. 
Figura 2. Distribuição dos teores do oxigênio dissolvido (OD) nas águas superficiais por ponto amostral.

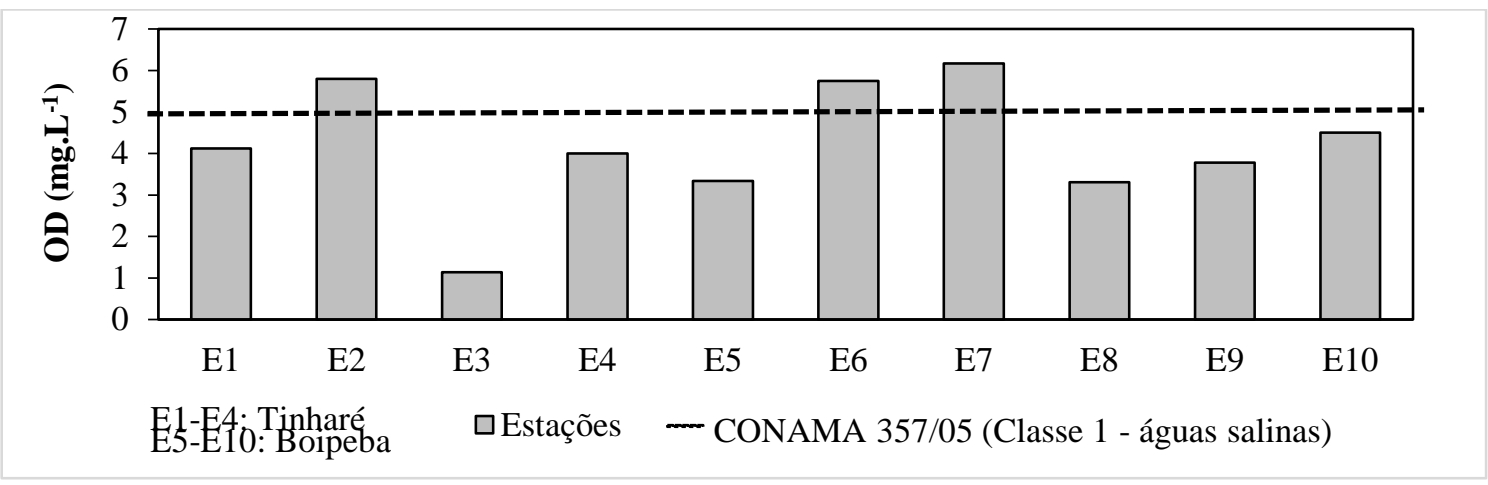

Fonte: Elaborado pelos autores.

Nos pontos amostrais E3 e E4 (3 ${ }^{a}$ e 4a Praias), observa-se que, além da perda da qualidade microbiológica da água, os níveis de OD estão em desacordo com o que dispõe a Resolução Conama no 357/05 (BRASIL, 2005) (Tabela 4; Figura 2). Esta situação indica haver uma perda da qualidade da água e riscos à saúde dos banhistas, pescadores, marisqueiros, o que demanda pelo monitoramento da balneabilidade das águas do mar, piscinas nos recifes e estuários e da qualidade das águas doces interiores.

Dawson e Sartory (2000) e Leão et al. (2018) assinalam que o consumo de água com restrição de potabilidade quanto aos coliformes termotolerantes representa risco à saúde. As bactérias Gramnegativas do grupo dos coliformes termotolerantes, em especial a Escherichia coli, indicam contaminação fecal humana recente e a provável presença de patógenos na água, bactérias, vírus entéricos, etc. (AMARAL et al., 2005).

Tabela 4. Medidas de coliformes em águas superficiais da localidade de Morro de São Paulo.

\begin{tabular}{c|c|cccc}
\hline Pontos & Local & Tubos (+) & NMP/100 ml & Tubos (+) & NMP/100 ml \\
\hline P01 & Córrego na Primeira Praia (E3) & 5 & $>16.00$ & 5 & $>16.00$ \\
P02 & Água Superficial na Segunda Praia (E3) & 5 & $>16.00$ & 5 & $>16.00$ \\
P03 & Córrego na Terceira Praia (E4) & 5 & $>16.00$ & 5 & $>16.00$ \\
P04 & Córrego na Quarta Praia (E4) & 5 & $>16.00$ & 5 & $>16.00$ \\
P05 & Água da Torneira (EMBASA) & 3 & 2.20 & 3 & 2.20 \\
\hline
\end{tabular}

Fonte: Autores, 2021.

As amostras dos pontos amostrais E2, E6 e E7 apresentaram níveis de OD indicativos de uma melhor qualidade da água, explicados, em parte, a influência das águas marinhas (Figura 2). Assinala-se que a população de São Sebastião (E6), na ilha de Maré, não dispõe de esgotamento sanitário adequado (Tabela 2); bem como observou-se, na pesquisa de campo, pontos de despejo de efluentes líquidos in natura no mar nesta localidade, que compromete a qualidade ambiental e ameaça à saúde da 
população residente, dos visitantes, os usos das águas, os modos de vida pescador e marisqueiro e demanda por gestão ambiental e mudanças no saneamento e na educação.

\subsection{INDICADORES GEOECOLÓGICOS: BIOMETRIA E DIAGNOSE VISUAL FOLIAR}

A Figura 3 apresenta a distribuição dos valores da área foliar da $R$. mangle entre as estações amostrais, verificando-se maior desenvolvimento foliar nos pontos de coleta que se situam próximos às desembocaduras dos rios Bainema (E9), Catu (E8) e Santo (E10). Observou-se que as medianas da área foliar diferiram significativamente entre os pontos amostrais, de acordo com o teste de comparações múltiplas de Kruskal-Wallis.

Figura 3. Distribuição dos valores da área do limbo foliar da R. mangle na APA Tinharé-Boipeba.

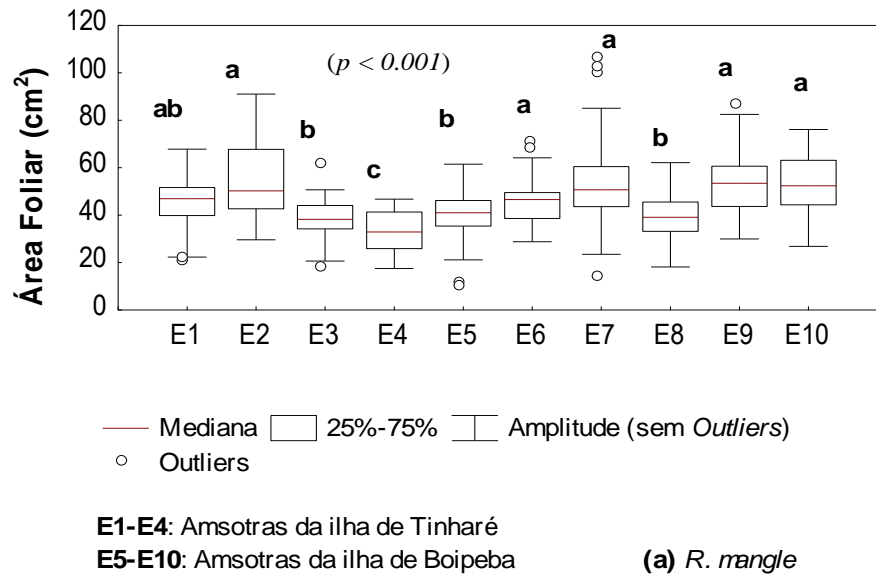

A Tabela 5 apresenta um resumo estatístico descritivo da área foliar, pela análise da diagnose foliar da Rhizophora na APA. A análise da morfologia externa das plantas contempla os métodos de diagnose visual, os quais descrevem as alterações na integridade do limbo foliar e na biometria do limbo foliar (MALAVOLTA, 2006).

Tabela 5. Sumário estatístico dos valores da área foliar $\left(\mathrm{cm}^{2}\right)$ da $R$. mangle da APA Tinharé-Boipeba,

Ba.

\begin{tabular}{cccccccc}
\hline Ponto Amostral & Mínimo & Máximo & Mediana & Média \pm EP & Desvio Padrão & CV (\%) & Shapiro-Wilk (valor de $p$ ) \\
\hline E1 - E4 (Tinharé) & 17.60 & 91.12 & 44.10 & $45.13 \pm 1.09$ & 14.60 & 32.34 & $p=0.006^{b}$ \\
E5 - E10 (Boipeba) & 9.68 & 105.70 & 47.84 & $48.75 \pm 0.81$ & 14.21 & 29.15 & $p<0.001^{b}$ \\
E1 - E10 (APA) & 9.68 & 105.70 & 46.35 & $47.40 \pm 0.66$ & 14.45 & 30.48 & $p=0.99^{a}$ \\
\hline
\end{tabular}

EP: erro padrão; CV: coeficiente de variação; ${ }^{a}$ distribuição gaussiana; ${ }^{b}$ distribuição não gaussiana.

A biometria foliar tem sido usada como indicador ecológico-geoambiental, cuja redução da área decorre da ação de estressores crônicos, como metais-traço em níveis tóxicos, salinidade, aporte de matéria orgânica, herbivoria e parasitismo (NEUMANN, 1993; SCHAEFFER-NOVELLI, 1995; SILVA; 
MARTINS; CAVALHEIRO, 2010). Larcher (2000) explica que o estresse na planta representa um estado no qual o aumento da demanda energética leva a perda de estabilidade inicial de suas funções, que se segue pela normalização e pelo aumento da resistência conforme a plasticidade metabólica.

No contexto de caracterização ecológico-geoambiental, fez-se a classificação das alterações na integridade foliar da R. mangle, em ordem decrescente: clorose > manchas escuras > pastejo (herbivoria), perfurações, necrose > galhas (Figura 4). Os estressores naturais ou antrópicos podem causar alterações anatômicas, morfológicas e fisiológicas nos órgãos e no desenvolvimento das plantas (BLOM, 1999; MARTINS et al, 2007).

Observou-se na análise de campo ou laboratorial que as amostras de folhas dos pontos E1, E3 e E10 revelaram as mais pronunciadas alterações na integridade foliar. Assinala-se que os problemas de nutrição mineral e a influência da salinidade explicam, em parte, a clorose (despigmentação) no bosques de mangue da APA Tinharé-Boipeba.

Figura 4. Comparação dos valores do índice de integridade do limbo foliar (IF) das alterações do limbo foliar da Rhizophora mangle nos bosques de mangue das Ilhas de Tinharé e Boipeba..

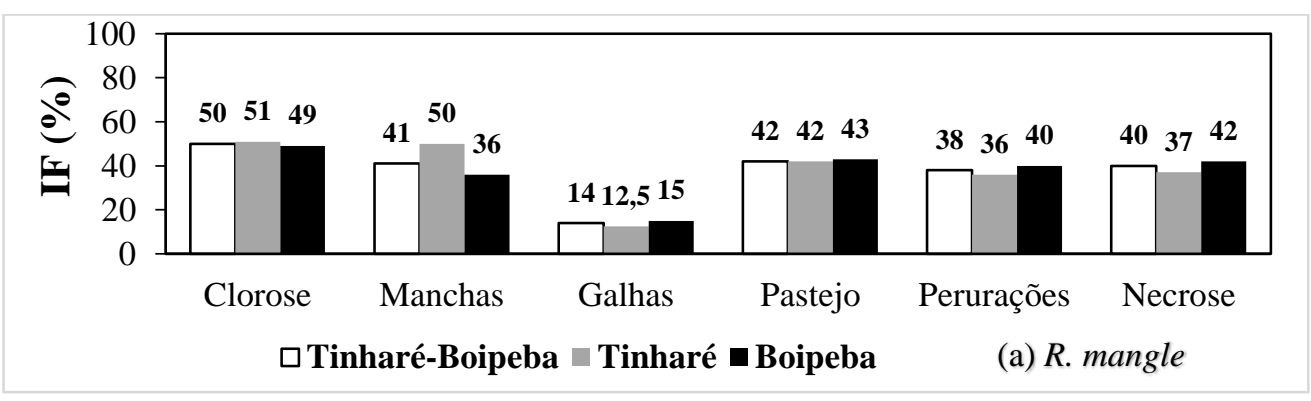

No presente estudo, obteve-se um perfil alterações foliares diferente ao perfil de bosques de mangue da Bahia de Todos os Santos (BTS), Bahia, obtidos a partir das pesquisas científicas realizadas por Garcia (2005), Andrade (2011) e Santos (2013). Andrade (2011) e Andrade et al. (2012) avaliou a integridade foliar do manguezal do rio Passa Vaca, sob a influência dos impactos decorrentes dos usos do solo e dos despejos de efluentes líquidos ("esgotos") in natura na área de drenagem do rio Passa, Salvador, Bahia. Obteve, em ordem decrescente de intensidade das alterações foliares: necrose inicial (23-30, mediana: 26,5) > manchas escuras (15-23, mediana: 18), perfurações (2 -13, mediana de 9), necrose avançada (8-15, mediana: 11$)$ > clorose (4 - 15, mediana: 4$)$.

Santos (2013) estudou os bosques de mangue de Madre de Deus e São Francisco do Conde, na Baía de Todos os Santos (BTS), Bahia, Brasil, encontrando, em ordem decrescente, as seguintes alterações na integridade do limbo foliar da R. mangle: necrose (23-30 folhas) > perfurações (pastejo) (8-15 
folhas) > herbivoria (8-15 folhas) > clorose e galhas (0-8 folhas). As perfurações, a necrose e herbivoria ocorreram em todas as estações amostrais. Este cenário não se aplica nas proximidades de fontes de poluição, como foi demonstrado por Garcia (2005). Estes bosques de mangue estão há cinco décadas expostos aos impactos da petroquímica e dos usos e da ocupação do solo.

\subsection{METAIS-TRAÇOS E AVALIAÇÃO BIOGEOQUÍMICA}

A análise da Figura 5 e da Tabela 7 revela que os teores dos metais-traço nas folhas de mangue na maioria das amostras foram normais e não tóxicos, conforme a classificação de Ross (1994), exceto os teores do $\mathrm{Cu}$ no ponto E2. Outrossim, o teste de Mann-Whitney, aplicado para dados não paramétricos, indicou que as medianas dos metais-traços $\mathrm{Zn}(p=0,95), \mathrm{Cd}(p=0,98)$ e $\mathrm{Pb}(p=0,60)$ não diferiram significativamente entre as amostras das ilhas de Tinharé e de Boipeba. Em relação ao Cu, observa-se que as medianas diferiram significativamente entre as ilhas de Tinharé e Boipeba $(p=0,001)$.

Figura 5. Distribuição dos teores dos metais-traço micronutrientes $(\mathrm{Cu}, \mathrm{Zn})$ e dos metais-traço potencialmente tóxicos ( $\mathrm{Cd}$ e $\mathrm{Pb}$ ) nas folhas da Rhizophora mangle dos bosques de mangue da APA.

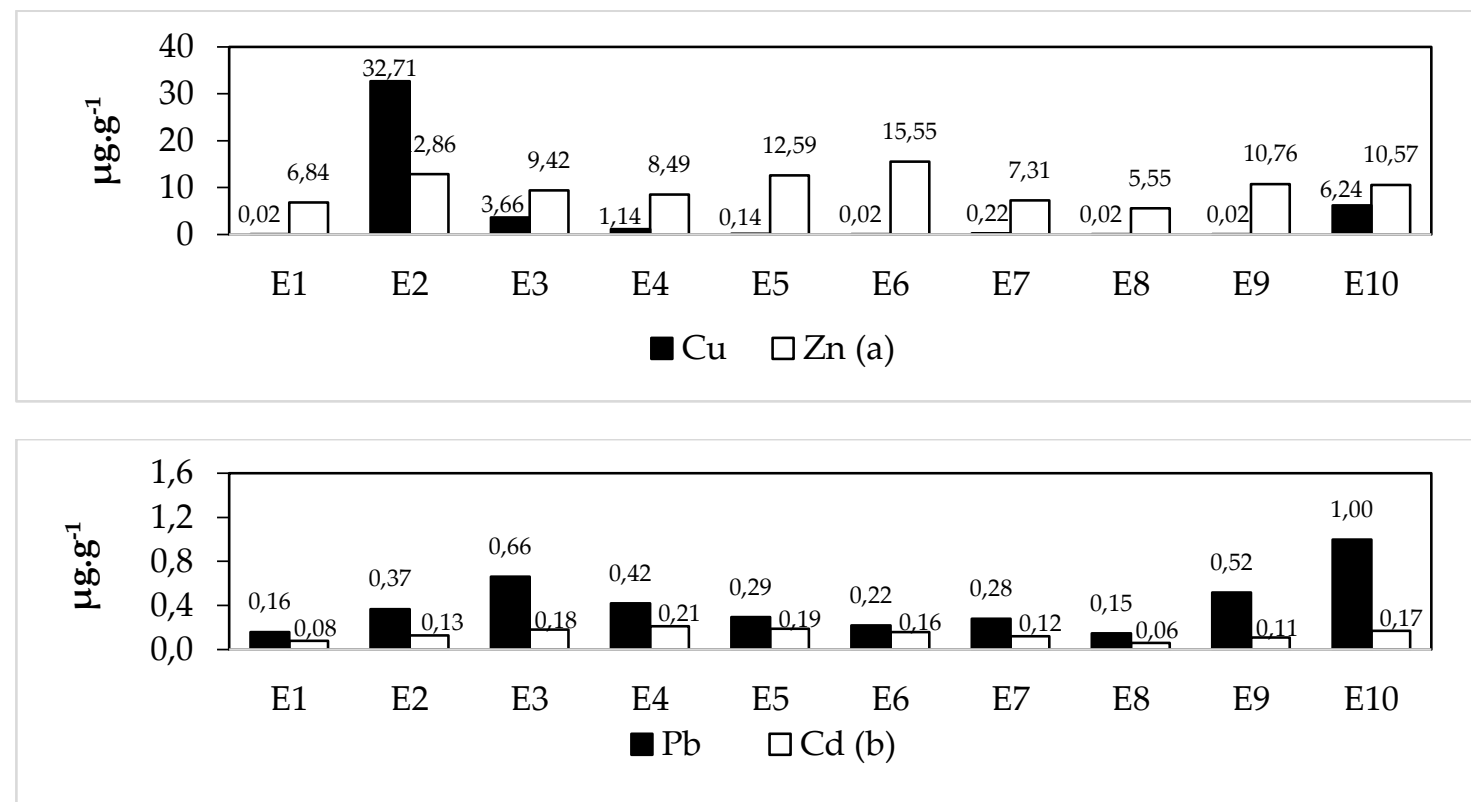

A Tabela 7 mostra o resumo estatístico dos níveis de metais-traço das folhas da $R$. mangle na APA Tinharé-Boipeba, que podem ser ordenados de forma decrescente: $\mathrm{Zn}>\mathrm{Cu}>\mathrm{Cd}>\mathrm{Pb}$. Houve teores situados abaixo do limite de detecção do método analítico para o metal-traço Cu (E1, E5, E6, E8, E9). Os valores das medianas dos micronutrientes $\mathrm{Cu}$ e $\mathrm{Zn}$ foram, no geral, inferiores ao valor ótimo de Hopkins (2000). 
Tabela 7. Sumário estatístico dos teores dos metais-traço em folhas da $R$. mangle.

\begin{tabular}{|c|c|c|c|c|c|c|c|c|c|c|}
\hline \multirow[b]{2}{*}{ Metais-Traço } & \multicolumn{3}{|c|}{ Limites de Toxidade } & \multicolumn{7}{|c|}{ Análise Descritiva } \\
\hline & $\begin{array}{c}\text { Normais } \\
\text { (Ross, 1994) } \\
\end{array}$ & $\begin{array}{c}\text { Tóxicos } \\
\text { (Ross, 1994) } \\
\end{array}$ & $\begin{array}{c}\text { Ótimo } \\
\text { (Hopkins, 2000) }\end{array}$ & Mín. & Máx. & Mediana & $\begin{array}{c}\text { Média } \pm \\
\text { Erro Padrão }\end{array}$ & DP & $\mathrm{CV}(\%)$ & $\begin{array}{c}\text { Shapiro-Wilk } \\
(\text { valor de } p)\end{array}$ \\
\hline & 4.00 & 20.00 & 6.00 & & & & $12.66 \pm 4.31$ & 15.54 & & $0.01^{\mathrm{b}}$ \\
\hline $\mathrm{Zn}(\mu$ & $8.00-400.00$ & $>400.00$ & 20.00 & 2.54 & 17.13 & 8.96 & $9.73 \pm$ & 4.04 & 41.5 & $0.04^{\mathrm{b}}$ \\
\hline $\mathrm{Cd}(\mu$ & $0.02-0.80$ & $5.00-30.00$ & - & 0.02 & 0.22 & 0.15 & $0.13 \pm 0.01$ & 0.06 & 46.34 & $0.02^{\mathrm{b}}$ \\
\hline $\mathrm{Pb}\left(\mu \mathrm{g} \cdot \mathrm{g}^{-1}\right)$ & $1.00-30.00$ & $30.00-300.00$ & - & 0.14 & 2.50 & 0.31 & $0.41 \pm 0.08$ & 0.43 & 107.1 & $0.006^{\mathrm{b}}$ \\
\hline
\end{tabular}

DP: desvio padrão; CV: coeficiente de variação; ${ }^{a}$ distribuição gaussiana; ${ }^{b}$ distribuição não gaussiana.

Encontrou-se os valores Fator de Concentração (FC) dos metais-traço inferiores a 1,0, com isso, inferese que os teores dos metais-traço estudados sejam maiores no sedimento que nas plantas, devendo não encontrar-se na forma biodisponível (Tabela 8). Salisbury e Ross (2012) compreendem que o cálculo do Fator de Concentração (FC) ao relacionar os níveis de um certo metal na folha de uma planta e no substrato fornece informações ecológico-geoambientais adicionais em uma investigação biogeoquímica.

Tabela 8. Metais-traço avaliados (média \pm erro padrão) nas folhas da $R$. mangle, teores nos sedimentos, folhelho padrão e fator de concentração (FC) na APA Tinharé-Boipeba.

\begin{tabular}{|c|c|c|c|c|c|}
\hline Metais-traço $\left(\mu . g . L^{-1}\right)$ & Folhas & Sedimento $^{\mathrm{a}}\left(\boldsymbol{\mu}\right.$. g. $\left.^{-1}\right)$ & Folhas & Folhelho Padrão $^{\text {b }}\left(\mu . g . L^{-1}\right)$ & Folhas \\
\hline $\mathrm{Cu}$ & $12.66 \pm 9.73$ & 18.35 & 0.77 & 45.00 & 0.28 \\
\hline Zn & $9.73 \pm 0.71$ & 81.00 & 0.21 & 95.00 & 0.11 \\
\hline Cd & $0.13 \pm 0.01$ & 0.25 & 0.52 & 0.30 & 0.43 \\
\hline $\mathbf{P b}$ & $0.41 \pm 0.08$ & 28.00 & 0.01 & 20.00 & 0.02 \\
\hline
\end{tabular}

aTurekian \& Wedepohl (1961); b Baía de Camamu - Zona Estuarina (OLIVEIRA et al., 2009).

Lacerda et al. (1986) encontraram valores do FC dos metais-traço $\mathrm{Cu}, \mathrm{Zn}, \mathrm{Cd}$ e $\mathrm{Pb}$ maiores do que 1,0 (unidade) em áreas de mangue no Sudeste do Brasil. Oliveira (2000), Andrade et al. (2012), Santos (2013); Leão et al. (2008); Gonçalves et al. (2020) obtiveram valores do FC < 1,0 em áreas de mangue da Bahia (Tabela 9). Lacerda (1997) destaca que um baixo valor do FC sugere que a planta evita a absorção de metais-traço.

Deve-se refletir sobre o papel da formação das placas de ferro como barreira geoquímica à translocação de metais-traço da rizosfera às folhas de mangue na APA, porque reduz a solubilidade e a toxicidade dos metais Fe e Mn, forma-se o óxido de ferro - placas de ferro na superfície da raiz, imobiliza-se e (co) precipita-se os metais. No manguezal, a deposição de óxidos e hidróxidos de Mn e Fe nos solos, e nos sedimentos, é favorecida pela respiração das raízes de plantas de mangue, as quais oxidam suas rizosferas e, com isso, transformam o sulfeto em sulfato (PI et al., 2011).

Infere-se o papel dos sedimentos e da rizosfera na biogeoquímica dos metais-traços na APA, cabendo ressaltar o papel da disposição espacial do ponto amostral ao longo da área de ocorrência das espécies 
de mangue e das marés. MacFarlane, Koller e Blomberg (2007), Kr'bek et al. (2011) e Einollahipeer et al. (2013) ressaltam a relevância da interação planta-sedimento do manguezal na acumulação de metais-traço, e destacam o serviço ofertado pelo manguezal de filtro geoambiental contra poluentes. Verifica-se, no presente estudo, que os teores dos metais-traço investigados não foram considerados tóxicos, podendo, localmente, os nutrientes $\mathrm{Cu}$ e Zn apresentarem-se abaixo do limite ótimo, o que pode influenciar, com base em Ernst, Verkleij e Schat (1992), Epstein e Bloom (2006), Broadley et al. (2007) e Parvaresh et al. (2011) no crescimento vegetal, na frutificação, redução da área foliar e na integridade (clorose). Assinala-se, também, que o potencial ecotoxicológicos dos metais $\mathrm{Cd}$ e $\mathrm{Pb}$ nas plantas de mangue da APA depende, além da salinidade, das marés, condições de oxirredução e pH do meio, do metabolismos vegetal e das condições biogeoquímicas da rizosfera.

\section{CONCLUSÕES}

A perda de qualidade das águas superficiais costeiras demandam por gestão ambiental e por intervenções no saneamento ambiental, elaboração de soluções técnicas compatíveis com os usos da natureza e modos de vida na APA Tinharé-Boipeba. Os bosques de mangue não se encontram impactados com níveis tóxicos dos metais-traço potencialmente tóxicos ( $\mathrm{Pb}$ e $\mathrm{Cd}$ ) e nutrientes minerais $(\mathrm{Cu}, \mathrm{Cd})$, cabendo um programa de monitoramento dos metais-traço nas folhas de mangue, fauna, água e sedimentos.

Com isso, a análise dos níveis de metais-traço nas folhas da Rhizophora mangle e do fator de concentração sugeriram que os fatores biogeoquímicos locais controlam a disponibilidade e mobilidade dos metais-traço, que podem ser retidos na rizosfera, ou imobilizadas nos tecidos. Assim, ressalta-se a relevância da biogeoquímica para gestão costeira, conservação ambiental e desenvolvimento social na APA Tinharé-Boipeba.

\section{AGRADECIMENTOS}

Agradece-se à FAPESB pelo financiamento do Projeto Avaliação dos Possíveis Impactos das Atividades de Petróleo e Gás nas Ilhas de Tinharé e Boipeba, Cairu, Bahia. 


\section{REFERÊNCIA}

ABOU SEEDO, K.; ABIDO, M. S., SALIH, A. A.; ABAHUSSAIN, A. Assessing heavy metals accumulation in the leaves and sediments of urban mangroves (Avicennia marina (Forsk.) Vierh.) in Bahrain. International Journal of Ecology, v. 24, n. 1, p. 35-52, 2017.

ACSELRAD, Henri. As práticas espaciais e o campo dos conflitos ambientais. Conflitos ambientais no Brasil. In: ACSELRAD, Henri (Org.). Conflitos Ambientais no Brasil. Rio de Janeiro: Relume Dumará/FASE, p. 13-35, 2004.

AJARA, Cesar. As difíceis vias para o desenvolvimento sustentável: gestão descentralizada do território e zoneamento ecológico-econômico. Rio de Janeiro: Escola Nacional de Ciências Estatísticas, no..8, 2003.

ALENCAR, C. M. M. Tensões entre pesca, turismo e exploração de gás reconfigurando ruralidade na ilha de Boipeba-BA. Desenvolvimento e Meio Ambiente, v. 23, p. 149-166.

ALEMU, J. B.; RICHARDS, D. R.; GAW, L. Y. F.; MASOUDI, M.; NATHAN, Y.; FRIESS, D. A. Identifying spatial patterns and interactions among multiple ecosystem services in an urban mangrove landscape. Ecological Indicators, v. 121, p. 107042, 2021.

AMARAL, L.A. ROSSI JR, O.D.; NADER FILHO, A; SOUZA, M.C.I. de; ISA, H. Água utilizada em suinocultura como fator de risco à saúde humana e animal. Arquivos Veterinária, Jaboticabal, SP, v. 21, n 1, p. 4146, 2005.

ANDRADE, C. L. N.; CELINO, J. J.; BARBOSA, R. M.; GARCIA, K. S.; ESCOBAR, N. F. C. Biogeoquímica da matéria orgânica e metais em um manguezal na zona estuarina urbana, Bahia, Brasil. Geonomos, v.20, n. 2, p. 34-43, 2012.

ANDRADE, C. L. N. Biogeoquímica do ambiente estuarino do rio passa vaca em área urbana de Salvador, BA. Dissertação (Mestrado), Universidade Federal da Bahia, Salvador, Bahia.

ANNEBOINA, L. R.; KUMAR, K. S.K. Economic analysis of mangrove and marine fishery linkages in India. Ecosystem services, v. 24, p. 114-123, 2017.

APHA - American Public Health Association; AWWA - American Water Works Association; WEF - Water Environment Federation. Standard methods for examination of water and wastewater. 21. ed. Washington, USA: D.C. APHA, 2005.

BARBOSA, J.S.F.; DOMINGUEZ, J.M.L. (Coords.). Texto Explicativo para o Mapa Geológico do Estado da Bahia. Escala 1: 1.000.000. Salvador: - SGM/PPPG/FAPEX, 1996. 295 p.

BARBAULT, Robert. Ecologia geral: estrutura e funcionamento da biosfera. Petrópolis, Rio de Janeiro: Vozes, 2011.

BATISTA, F. S.; JUNIOR, A. B. D. S. R.; CRUZ, M. J. M.; SANTOS, R. A. Condições de saneamento e qualidade das águas subterrâneas de municípios do oeste da Bahia (BR). Geoingá: Revista do Programa de Pós-Graduação em Geografia (PGE/UEM), v. 13, n. 1, p. 202-224, 2021. 
BLOM, C. W. P. M. Adaptations to Flooding Stress: From Plant Community to Molecule. Plant biology, v.1, n.3, p.261-273, 1999.

BRANDER, L. M.; WAGTENDONK, A. J.; HUSSAIN, S. S.; MCVITTIE, A.; VERBURG, P. H.; DE GROOT, R. S.; VAN DER PLOEG, S. Ecosystem service values for mangroves in Southeast Asia: A meta-analysis and value transfer application. Ecosystem Services, v. 1, n. 1, p. 62-69, 2012.

BRASIL. Projeto Ilhas de Tinharé e Boipeba, Área de Proteção Ambiental. Etapa I. Diagnóstico Ambiental. Volume II, Estudos do meio físico, Salvador: Companhia de Desenvolvimento da Região Metropolitana de Salvador (CONDER); Centro de Recursos Ambientais (CRA); Companhia de Pesquisas de Recursos Minerais (CPRM), 1995.

BRASIL. Ministério do Meio Ambiente. Conselho Nacional do Meio Ambiente (CONAMA). Resolução no 357, de 17 de março de 2005. Dispõe sobre a classificação dos corpos de água e diretrizes ambientais para o seu enquadramento, bem como estabelece as condições e padrões de lançamento de efluentes, e dá outras providências. Diário Oficial da União, Brasília, 2005.

BRASIL. Congresso Nacional. Lei 12.305, 2 de agosto de 2010. Institui a Política Nacional de Resíduos Sólidos; altera a Lei no 9.605, de 12 de fevereiro de 1998; e dá outras providências. Diário Oficial da União, Brasília, 2010.

BROADLEY, M.R.; WHITE, P.J.; HAMMOND, J.P.; ZELKO, I.; LUX, A. Zinc in plants. New Phytol, v.173, n.4, p. 677-702, 2007.

CAMARGO, A. B. A. D.; CAPOBIANCO, J. P. R.; OlIVEIRA, J. A. P. D. Meio Ambiente Brasil: Avanços e Obstáculos Pós-Rio-1992. 2 ed. In: Meio Ambiente Brasil: Avanços e Obstáculos Pós-Rio-1992. Rio de Janeiro: Fundação Getúlio Vargas, 2004, p. 471-471.

CHAPMAN, P.M.; WANG, F. Assessing sediment contamination in estuaries. Environmental Toxicology and Chemistry, v. 20, n. 1, p. 3-22, 2001.

DALY, H.; FARLEY, J. Economia ecológica: princípios e aplicações. Lisboa: Instituto Piaget, 2004.

DAWSON, D. J.; SARTORY, D. P. Microbiological safety of water. Br Med Bull, n. 56, v.1, p.74-83, 2000

EINOLLAHIPEER, F.; KHAMMAR, S.; SABAGHZADEH, S. A study on heavy metal concentration in sediment and mangrove (Avicenia marina) tissues in Qeshm island, Persian Gulf. Journal of Novel Applied Sciences, v.2, n.10, p. 498-504, 2013.

ELLIFF, C.I.; KIKUCHI, R.K. Ecosystem services provided by coral reefs in a Southwestern Atlantic Archipelago. Ocean \& Coastal Management, v.136, p. 49-55, 2017.

EPSTEIN, E.; BLOOM, A. J. Nutrição mineral de plantas. Londrina: Planta, 2006.

ERNST, W.H.O.; VERKLEIJ, J.A.C.; SCHAT, H. Metal tolerance in plants. Acta Botanica Neerlandica, v. 41, n. 3, p. 229-248, 1992.

GARCIA, K. S. Estudos biogeoquímicos em folhas de Avicennia shaueriana Stapf \& Leechman em zonas de manguezal da região de São Francisco do Conde e Madre de Deus-BA. Dissertação (Mestrado), Universidade Federal da Bahia, Salvador, 2005. 
GONÇALVES, M. P.; SILVA, I. R.; RAMOS, A. B. D. S.; SANTOS, R. A.; PAIXÃO, L. H. C.; ALENCAR, C. M. M. D.; ALVA, J. C. R. Qualidade das águas e análise de metais em folhas de mangue na APA TinharéBoipeba (BA). Engenharia Sanitária e Ambiental, v. 25, p. 583-596, 2020.

GONÇALVES, M. V. P.; SANTOS, R. A.; CRUZ, M. J. M.; PORCIÚNCULA, D. C. L. Condições Sociais de Saúde, Saneamento e Qualidade das Águas Subterrâneas de Itaparica e Vera Cruz, Região Metropolitana de Salvador, Bahia (BR). Geoingá: Revista do Programa de Pós-Graduação em Geografia (PGE/UEM), v. 13, n. 1, p.121-145, 2021.

HOLMLUND, Cecilia M.; HAMMER, Monica. Ecosystem services generated by fish populations. Ecological economics, v. 29, n. 2, p. 253-268, 1999.

HOPKINS, W.G. Introduction to plant physiology. 2. ed. Nova York: John Wiley \& Sons, 2000.

IBGE - Instituto Brasileiro de Geografia e Estatística. Dados do Censo demográfico 2010. Publicados no Diário Oficial da União do dia 24/11/2010.

IBGE - Instituto Brasileiro de Geografia e Estatística. Cidades e Estados do Brasil. Disponível em: https:// cidades.ibge.gov.br/brasil/ba/Salvador/BA/panorama. Acessado em: 22 agosto de 2019.

IGNÁCIO, G.M.; DOMINGUES, D.; LANA, P.C.; CARRILHO, J. C. Variação nos níveis de herbivoria foliar em dois manguezais da baía de Paranaguá (Paraná - Brasil). Brazilian Journal of Aquatic Science and Technology, v.9, n.2, p.1-4, 2005.

KŘÍBEK, B.; MIHALJEVIČ, M.; SRACEK, O.; KNÉSL, I.; ETTLER, V.; NYAMBE, I. The extent of arsenic and of metal uptake by aboveground tissues of Pteris vittata and Cyperus involucratus growing in copper-and cobalt-rich tailings of the Zambian Copperbelt. Archives of Environmental Contamination and Toxicology, v.61, n.2, p.228-242, 2011.

KUMAR, I. N.; SAJISH, P. R.; KUMAR, R.N.; BASIL, G.; SHAILENDRA, V. As Assessment of the Accumulation Potential of $\mathrm{Pb}, \mathrm{Zn}$ and $\mathrm{Cd}$ by Avicennia marina (Forssk.) Vierh. In in Vamleshwar Mangroves, Gujarat, India. Notulae Scientia Biologicae, v.3, n.1, p. 323-326, 2011.

JESUS, H. C. D.; COSTA, E. D. A.; MENDONÇA, A. S. F.; ZANDONADE, E. Distribuição de metais pesados em sedimentos do sistema estuarino da Ilha de Vitória-ES. Química Nova, v. 27, p. 378-386, 2004.

LACERDA, L. D.; REZENDE, C. E.; JOSÉ, D. V.; FRANCISCO, M. C. F. Metallic composition of mangrove leaves from the southeastern Brazilian coast. Revista Brasileira de Biologia, v.46. n. 2, p. 395-399, 1986.

LACERDA, L. D. Trace metals in mangrove plants: why such low concentrations? In: Kjerfve, B.; Lacerda, L.D.; Diop, H.S. (Orgs.). Mangrove Ecosystem Studies in Latin America and Africa. Paris, Unesco, 1997. p. 171-178.

LARCHER, W. Ecofisiologia Vegetal. São Carlos: Rima, 2000.

LEÃO, C. S.; QUEIROZ, A.F.S.; CELINO, J.J.; HADLICH, G. M. Metais-traço no ecossistema manguezal da Baía de Aratu. In: QUEIROZ, A.F.S.; CELINO, J.J. (orgs.). Avaliação de Ambientes na Baía de Todos os Santos. Salvador: EDUFBA, 2008, p. 233-245. 
LEÃO, R. C.; GONÇALVES, Á. C.; SANTOS, C. T. B.; ANDRADE, A. A.; SILVA, M. C. S.; SILVA, M. B. O. Ocorrência de enteroparasitos e coliformes termotolerantes nas mãos de manipuladores de alimentos de um hospital de ensino. Cadernos Saúde Coletiva, n.26, v.2, p.211-215, 2018.

LESSA, C. M. Identificação de áreas prioritárias para a conservação da sociobiodiversidade na zona estuarina da Costa do Dendê, Bahia. Dissertação (Mestrado), Universidade de Brasília, Brasília: 2007.

MACFARLANE, G. R.; KOLLER, C. E.; BLOMBERG, S. P. Acumulação e partição de metais pesados em manguezais: uma síntese de estudos de campo. Chemosphere, v.69, n.9, p. 1454-1464, 2007.

MALAVOLTA, E. Manual de nutrição mineral de plantas. São Paulo, Agronômica Ceres, 2006.

MARTíNEZ-ALIER, J. Los conflictos ecológico-distributivos y los indicadores de sustentabilidad. Revibec: revista de la Red Iberoamericana de Economía Ecológica, v. 1, p. 021-30, 2004.

MARTINS, R.A.C.; BERNINI, E.; REZENDE, C. E. Biometria foliar e herbivoria de espécies do manguezal do estuário do rio Itabapoana, divisa entre os estados do Rio de Janeiro e Espírito Santo. In: Congresso Latino Americano de Ciências do Mar, 12, 2007, Florianópolis. Anais... Florianópolis: Associação Brasileira de Oceanografia, 2007.

MARTUTI, N. K. T.; WIDIANARKO, B.; YULIANTO, B. Translocation and Elimination of Cu in Avicennia marina. Pertanika Journal of Tropical Agricultural Science, n.40, p.2, p. 285-294, 2017.

NEUMANN, P. M. Rapid and reversible modifications of extension capacity of cell walls in elongating maize leaf tissues responding to root addition and removal of $\mathrm{NaCl}$. Plant, Cell \& Environment, v.16, n.9, p.1107-1114, 1993.

OLIVEIRA, O.M.C. de. Diagnóstico Geoambiental em zonas de manguezal da Baía de Camamu - BA. Tese (Doutorado) - Universidade Federal Fluminense, Rio de Janeiro, 2000.

OLIVEIRA, O. M. C.; CRUZ, M. J. M.; QUEIROZ, A. F. S. Comportamento geoquímico de metais em sedimentos de manguezal da Baía de Camamu-Bahia. Brazilian Journal of Aquatic Science and Technology. Braz. J. Aquat. Sci. Technol., v. 13, n. 2, p. 1-8, 2009.

PAIXÃO, L.H.C. Atividade pesqueira no mundo rural contemporâneo do município de Cairu/Ba. Dissertação (Mestrado), Universidade Católica do Salvador, Salvador, 2015.

PAIXÃO, L. H. C.; DE ALENCAR, C. M. M.; GONÇALVES, M. V. P. Dinâmica pesqueira de Gamboa no mundo rural costeiro do Município de Cairu-BA. Seminários Espaços Costeiros, 2016.

PARVARESH, H.; ABEDI, Z.; FARSHCHI, P.; KARAMI, M.; KHORASANI, N.; KARBASSI, A. Bioavailability and concentration of heavy metals in the sediments and leaves of grey mangrove, Avicennia marina (Forsk.) Vierh, in Sirik Azini Creek, Iran. Biological Trace Element Research, v.143, n.2, p. 1121-1130, 2011.

PELLEGRINI, J.A.C.; CASTRO, E.M.N.V.; CASTRO, K.N.; SOARES, M.L.G. Tensionamentos socioambientais em comunidades costeiras: um estudo interdisciplinar nos manguezais do sul da Bahia. Ambiente \& Sociedade. São Paulo, v. 23, p. 1-19, 2020.

ROSS, S. M. Toxic metals in soil-plant systems. Nova Nova York: John Wily e Sons, 1994. 
RUSCHEINSKY, A. No conflito das interpretações: o enredo da sustentabilidade. Sustentabilidade: uma paixão em movimento. Rev. Eletrônica Mestr. Educ. Ambient., v. 10, p.39-50, 2003.

SANT'ANNA PORTO, José Renato. Expansão do turismo, conflitos territoriais e resistência quilombola no Baixo Sul da Bahia. Revista del CESLA. International Latin American Sudies Review, v. 23, p. 301332, 2019.

SANTOS, L. O. Disponibilidade de elementos químicos em apicuns e em sedimentos e folhas de manguezais do município de Madre de Deus, Bahia, Brasil. Dissertação (Mestrado), Universidade Federal da Bahia, Salvador, Brasil, 2013.

SANTOS, M. O dinheiro e o Território. In: Santos, M. (Orgs.). Território, territórios: ensaios sobre ordenamento territorial. Rio de Janeiro: Editora Lamparina; p. 13-21, 2007.

SEI. Superintendência de Estudos Econômicos. Cairu. In: Estatísticas dos Municípios Baianos. v.4. Salvador: SEI, 2014. p. 37-55.

SILVA, I. R.; SILVA, S.B.M. Caracterização geo-ambiental e de ocupação das praias da costa do dendê, litoral sul do estado da Bahia. Geosul (UFSC), v. 22, n. 44, p. 27-46, 2007.

SILVA, I. R.; ROSSI, J. C.; NASCIMENTO, H. M.; SIQUEIRA, T. G. Geoenvironmental Characterization and Urbanization of the Beaches on the Islands of Tinhare and Boipeba, South Coast of the State of Bahia, Brazil. Journal of Coastal Research, v.SI 56, p. 1297-1300, 2009.

SALISBURY, F. B.; ROSS, C. W. Fisiologia das plantas. 4 ed. São Paulo: Cengage Learning, 2012.

SANT'ANNA PORTO, José Renato. Expansão do turismo, conflitos territoriais e resistência quilombola no Baixo Sul da Bahia. Revista del CESLA. International Latin American Sudies Review, v. 23, p. 301332, 2019.

SANTOS, L. O. Disponibilidade de elementos químicos em apicuns e em sedimentos e folhas de manguezais do município de Madre de Deus, Bahia, Brasil. Dissertação (Mestrado), Universidade Federal da Bahia, Salvador, Brasil, 2013.

SCHAEFFER-NOVELLI, Y. Manguezal: ecossistema entre a terra e o mar. São Paulo: Caribbean Ecological Research, 1995.

SILVA, J. N.; MARTINS, M. B. G.; CAVALHEIRO, A. J. Caracterização anatômica e perfil químico da lâmina foliar de Laguncularia racemosa (L.) Gaertn, de manguezais impactados e não impactados do litoral de São Paulo. Iheringia, Série Botânica, Porto Alegre, v.65, n.2, p. 123-132, 2010.

TUREKIAN, K. K.; WEDEPOHL, K. H. Distribution of the elements in some major units of the earth's crust. Geological Society of America Bulletin, v.72, n.2, p. 175-192, 1961.

ZHANG, Y.; YU, C.; XIE, J.; DU, S.; FENG, J.; GUAN, D. Comparison of fine root biomass and soil organic carbon stock between exotic and native mangrove. Catena, v. 204, p. 105423, 2021. 


\section{Capítulo 3}

d.

REVISÃO ESTRATIGRÁFICA DAS UNIDADES SUPERIORES DO SEGMENTO E-W DA FAIXA PARAGUAI: LITOESTRATIGRAFIA,

QUIMIOESTRATIGRAFIA E GEOCRONOLOGIA, MT

- BRASIL.

Samille Cristine dos Reis de Souza

Carlos José Souza de Alvarenga
Universidade de Brasília

Universidade de Brasília 
Resumo: A Faixa Paraguai apresenta diversas interpretações/controvérsias quanto sua evolução. Para melhor posicionar seus depósitos superiores, realizou-se revisão estratigráfica, considerando literatura disponível, levantamento litoestratigráfico, quimioestratigráfico (C e Sr) e geocronológico $(\mathrm{U}-\mathrm{Pb})$. No segmento E-W da faixa, arredores de Planalto da Serra-MT, afloram pelitos carbonáticos/calcários estromatolíticos da Formação Pacu, topo do Grupo Araras; seguido de diamictitos-ritmitos sobre limite bem marcado da base da Formação Serra Azul, limitada acima pelos arenitos-pelitos da Formação Raizama (Ciclos A-D) e ao topo arcóseos-pelitos da Formação Diamantino, Grupo Alto Paraguai. A Formação Pacu apresenta $\delta 13 \mathrm{C}$ de $+6.5 \%$ a $+8.9 \%$ e razões 87Sr/86Sr entre $0.7087-0.7088$. Valores $\delta 13 \mathrm{C}$ são distintos daqueles encontrados no restante do Grupo Araras. Razões 87Sr/86Sr, analisadas na curva global marinha de razões isotópicas de Sr, apresentam valores compatíveis ao final do Ediacarano, embora a Formação Pacu esteja estratigráficamente abaixo da Formação Serra Azul, correlata a Glaciação Gaskiers (582Ma). Idades U$\mathrm{Pb}$ em zircões detríticos mostram mudanças de áreas fontes da Formação Diamantino, indicando inversão de fonte de norte-noroeste para leste-sudeste. 


\section{INTRODUÇÃO}

A Faixa Paraguai, contém registros dos eventos glaciais globais Neoproterozóicos, incluindo sedimentação que avançou até o limite Neoproterozóico-Cambriano Inferior (Nogueira et al., 2003, 2007a; Figueiredo et al., 2004, 2008, 2011; Alvarenga et al., 2007, 2008; Dantas et al., 2009; McGee et al., 2015a,b). Trabalhos geológicos apresentam a complexidade dos processos que ocorreram neste período, originando diversas interpretações/controvérsias quanto sua evolução.

Portanto, revisão estratigráfica no segmento E-W da faixa, arredores de Planalto da Serra-MT, associado ao levantamento litoestratigráfico, quimioestratigráfico ( $\mathrm{C}$ e $\mathrm{Sr}$ ) e geocronológico (U-Pb), provaram ser ferramentas importantes para correlações em escala regional/global.

\section{MATERIAIS E MÉTODOS}

Os dados foram tratados nos laboratórios do Instituto de Geociências da Universidade de Brasília-UnB. Foram realizadas análises texturais/composicionais via microscopia óptica, além de análise química em microssonda. Isótopos de C e O foram obtidos no Delta V Advantage conectado a Gas Bench II. Razões 87Sr/86Sr foram medidas em espectrômetro MC-ICP-MS Neptune Thermo.

Apenas os resultados dos isótopos de C e Sr foram aplicados na correlação estratigráfica e no estudo paleoambiental e paleoclimático. Idades U-Pb em zircões detríticos foram determinadas via LA-MCICP-MS.

\section{RESULTADOS E DISCUSSÃO}

A Formação Pacu, topo do Grupo Araras, é representada por laminito (Fácies $L m$ ) e argilito carbonático/silicificado laminado (Fácies Fl), Fácies Argilosa (base), de ambiente marinho raso a transicional, seguido de calcários estromatolíticos (Fácies Ls), Fácies Carbonática (topo), de plataforma carbonática rasa. Dados $\delta 13 \mathrm{C},+6.5 \%$ a $+8.9 \%$, diferem dos encontrados no restante deste grupo. Razões 87Sr/86Sr são semelhantes, entre 0.7087-0.7088 e, quando lançadas na curva global marinha de variação isotópica de Sr (Halverson et al., 2007b, 2010) indicam idade pós Glaciação Gaskiers. Ponderando recobrimento desses calcários pelos diamictitos correlatos a esta glaciação, se esperaria idade superior a $582 \mathrm{Ma}$.

A Formação Serra Azul, base do Grupo Alto Paraguai, individualizada em: 'Unidade A' (base), preenchida por diamictitos maciços (Fácies Dm) depositados por rain-out em ambiente glácio-marinho raso a transicional e; 'Unidade B' (intermediária/topo), formada por siltitos-ritmitos 
ondulados/retrabalhados por ondas. A transição Unidade A-B sugere interrupção da influência glacial, passando para ambiente marinho profundo influenciado por ondas. O contato superior, descrito como gradacional (Figueiredo et al., 2004, 2008; Alvarenga et al., 2007), é proposto como brusco (Seção 1), definido por banco de arenito que marca a base da Formação Raizama. Idades UPb 619 e 593Ma, a correlacionam com depósitos glaciais Ediacaranos, possivelmente contemporâneos a Glaciação Gaskiers (582Ma). Estas idades associadas a Sm-Nd TDM (Figueiredo, 2010) sugerem o Cráton Amazônico (Tassinari \& Macambira, 1999, 2004) como área fonte.

A Formação Raizama foi individualizada em ciclos (Ciclos A-D) na região de Planalto da Serra, já na região de "Sete Placas" os afloramentos descontínuos dificultaram individualização.

Compõem-se de intercalações rítmicas de pelito-arenito retrabalhados/truncados por estrutura de onda e com hummockys, em shoreface inferior dominado por onda e tempestade. Idades U-Pb 888 e 967Ma não representam idade de deposição, considerando que esta formação é mais jovem que a

Formação Serra Azul. Tais idades indicam que os sedimentos seriam provenientes em parte do Cráton Amazônico e região do Maciço de Goiás e Faixa Brasília.

Na Formação Diamantino, região de Planalto da Serra, siltitos laminados recobrem a Formação Raizama. Na região de "Sete Placas", pelitos avermelhados micáceos e arenitos com marcas de ondas simétricas, passam para siltitos/pelitos e arcóseos com mais de 5000m de espessura. Idades U-Pb 567 e 694Ma sugerem que a deposição no Grupo Alto Paraguai se estendeu até o Cambriano Inferior. Estas idades associadas a Sm-Nd TDM (Dantas et al., 2009) indicam mudança de fonte mais antiga a nortenoroeste, Cráton Amazônico, para fonte mais jovem a lestesudeste, Maciço de Goiás e Faixa Brasília, inferindo inversão tectônica da bacia.

\section{CONCLUSÕES}

- A Formação Pacu exibe $\delta 13 \mathrm{C}$ e razões $87 \mathrm{Sr} / 86 \mathrm{Sr}$ distintos dos encontrados no restante do Grupo Araras. As razões $87 \mathrm{Sr} / 86 \mathrm{Sr}$ comparadas as demais encontradas neste grupo mostram evolução para águas com razões isotópicas de Sr mais radiogênicas. A curva global marinha de razões isotópicas de Sr coloca os valores como pós Glaciação Gaskiers, entretanto o posicionamento estratigráfico logo abaixo da unidade considerada correlata a esta glaciação, sugere reavaliação/ampliação do banco de dados para melhor calibração temporal desta curva.

- O contato basal da Formação Serra Azul com o topo da Formação Pacu é discordante e bem marcado em campo. Enquanto que o contato superior com a base da Formação Raizama, descrito como 
gradacional na região de Marzagão (sessão tipo), se apresenta claramente como tipo brusco na região de Planalto da Serra (área de estudo).

- A Formação Raizama, na região de Planalto da Serra, possui boa continuidade estratigráfica, o que permitiu na "Seção 1" individualiza-la em quatro grandes ciclos (Ciclos A-D).

- Idades U-Pb em zircões detríticos da Formação Diamantino confirmam mudança de área fonte, sugerindo que a fonte principal desses sedimentos derivou de leste-sudeste, regiões do Maciço de Goiás e da Faixa Brasília, corroborando com a hipótese de inversão tectônica da bacia.

\section{AGRADECIMENTOS}

Ao Instituto de Geociências da Universidade de Brasília-Unb, PETROBRÁS e CAPES. 


\section{REFERÊNCIAS}

Alvarenga, C.J.S.; Figueiredo, M.F.; Babinski, M. \& Pinho, F.E.C. 2007. Glacial diamictites of Serra Azul Formation (Ediacaran, Paraguay Belt): evidence of the Gaskiers glacial event in Brazil. Journal of South American Earth Science, 23: 236-241.

Alvarenga, C.J.S.; Dardenne, M.A. et al. 2008. Isotope stratigraphy of Neoproterozoic cap carbonate in the Araras Group, Brazil. Gondwana Research, 13: 469-479.

Dantas, E.L.; Alvarenga, C.J.S.; Santos, R.V. \& Pimentel, M.M. 2009. Using Nd isotopes to understand the provenance of sedimentary rocks from a continental margin to a foreland basin in the Neoproterozoic Paraguay Belt, Central Brazil. Precambrian Research, 170: 1-12.

Figueiredo, M. F. 2010. Quimiestratigrafia isotópica (C, O, S e Sr), Geocronologia (Pb-Pb e K-Ar) e Proveniência ( $\mathrm{Sm}-\mathrm{Nd}$ ) das rochas da Faixa Paraguai Norte, Mato Grosso. Tese (Doutorado). São Paulo: Universidade de São Paulo, Instituto de Geociências.

Figueiredo, M.F; Babinski, M.; Alvarenga, C.J.S.; Pinho, F.E.C. 2004. Diamictites overlying Marinoanage carbonates of Araras Formation, Paraguay belt, Brazil: evidence of a new glaciation?. In: Symposium on Neoproterozoic-Early Paleozoic Events in SW-Gondwana, 1, Extended Abstracts, IGCP Project 478, Second Meeting, Brazil, p. 18-19.

Figueiredo, M.F.; Babinski, M.; Alvarenga, C.J.S. \& Pinho, F.E.C. 2008. Nova unidade litoestratigráfica registra glaciação ediacarana em Mato Grosso: Formação Serra Azul. Geologia USP, 8: 65-75.

Figueiredo, M.F.; Babinski, M.; Alvarenga, C.J.S. 2011. The Serra Azul Formation, Paraguay Belt, Brazil. Geological Society, London, Memoirs 2011; 36: 499-502.

Halverson, G.P.; Dudas, F.O.; Maloof, A.C.; Bowring, S.A. 2007b. Evolution of the $87 \mathrm{Sr} / 86 \mathrm{Sr}$ composition of Neoproterozoic seawater. Palaeogeogr. Palaeoclimatol. Palaeoecol. 256: 103- 129.

Halverson, G.P.; Hurtgen, M.T.; Porter, S.M.; Collins, A.C. 2010. Neoproterozoic-Cambrian biogeochemical evolution. In: Gaucher, C.; Sial, A.N.; Halverson, G.P.; Frimmel, H. (Eds.), Neoproterozoic-Cambrian Tectonics, Global Change and Evolution: A Focus on Southwestern Gondwana, Dev. Precambrian Geol. Elsevier, 16: 351-356.

Nogueira, A.C.R.; Riccomini, C.; Sial, A. N.; Moura, C.A.V. \& Fairchild, T. R. 2003. Softsediment deformation at the base of Neoproterozoic Puga cap carbonate (southwestern Amazon craton, Brazil): confirmation of rapid icehouse to greenhouse transition in snowball Earth. Geology, 31, 613-616.

Nogueira, A.C.R.; Riccomini, C.; Sial, A.N.; Moura, C.A.V.; Trindade, R. I. F. \& Fairchild, T. R. 2007a. Carbon and strontium isotope fluctuations and paleoceanographic changes in the late Neoproterozoic Araras carbonate platform, southern Amazon craton, Brazil. Chemical Geology, 80, 168-190.

McGee, B; Collins, A.S. \& Trindade, R.I.F. 2015a. Age and Provenance of the Cryogenian to Cambrian passive margin to foreland basin sequence of the northern Paraguay Belt, Brazil. Bull. Geol. Soc. Am., 127: 76-86.

McGee, B; Collins, A.S.; Trindade, R.I.F. \& Jourdan, F. 2015b. Investigating mid-Ediacarian glaciation and final Gondwana amalgamation using coupled sedimentology and 40Ar/39Ar detrital muscovite 
provenance from the Paraguay Belt, Brazil. International Association of Sedimentologists, Sedimentology, 62: 130-154.

Tassinari, C.C.G. \& Macambira, M.J.B. 1999. Geocronological Provinces of the Amazonian Craton. Episodes, 22(3):174-182.

Tassinari, C.C.G. \& Macambira, M.J.B. 2004. A evolução tectônica do Cráton Amazônico. In: MantessoNeto V. et al. 2004. Geologia do continente Sul Americano: uma evolução da obra de Fernando Flávio Marques de Almeida. São Paulo: Beca. P. 471-488. 